Published in final edited form as:

Nat Protoc. 2018 July ; 13(7): 1662-1685. doi:10.1038/s41596-018-0007-8.

\title{
Directed differentiation of human induced pluripotent stem cells into mature kidney podocytes and establishment of a Glomerulus Chip
}

\author{
Samira Musah ${ }^{1,2}$, Nikolaos Dimitrakakis ${ }^{1}$, Diogo M. Camacho ${ }^{1}$, George M. Church ${ }^{1,2}$, \\ Donald E. Ingber ${ }^{1,3,4}$ \\ ${ }^{1}$ Wyss Institute for Biologically Inspired Engineering at Harvard University, Boston, MA 02115 , \\ USA. \\ ${ }^{2}$ Department of Genetics, Harvard Medical School, Boston, MA 02115, USA. \\ ${ }^{3}$ Vascular Biology Program, Children's Hospital and Harvard Medical School, Boston, MA 02115, \\ USA. \\ ${ }^{4}$ Harvard John A. Paulson School of Engineering and Applied Sciences, Cambridge, MA 02139, \\ USA.
}

\section{Abstract}

Protocols have been established to direct the differentiation of human induced pluripotent stem (iPS) cells into nephron progenitor cells and organoids containing many types of kidney cells, but it has been difficult to direct the differentiation of iPS cells to form specific types of mature human kidney cells with high yield. Here, we describe a detailed protocol for the directed differentiation of human iPS cells into mature, post-mitotic kidney glomerular podocytes with high (>90\%) efficiency within 26 days, and under chemically-defined conditions without genetic manipulations or subpopulation selection. We also describe how these iPS cell-derived podocytes may be induced to form within a microfluidic organ-on-a-chip (Organ Chip) culture device to build a human kidney Glomerulus Chip that mimics the structure and function of the kidney glomerular capillary wall in vitro within 35 days (starting with undifferentiated iPS cells). The podocyte differentiation protocol requires skills for culturing iPS cells, and the development of a Glomerulus Chip requires some experience with building and operating microfluidic cell culture systems. This method could be useful for applications in nephrotoxicity screening, therapeutic development, and regenerative medicine, as well as mechanistic study of kidney development and disease.

\footnotetext{
Abstract

Address Correspondence to: Donald E. Ingber,M.D.,Ph.D. (don.ingber@wyss.harvard.edu).

Author contributions

S.M., G.M.C., and D.E.I. conceived the strategy for this study; S.M. designed and performed experiments; S.M. and D.E.I. wrote the manuscript; N.D. and D.M.C. independently analyzed the microarray data, and S.M. interpreted the results; N.D. generated heatmaps and corresponding statistical data sets. All authors discussed the results and commented on the manuscript.

Competing Financial Interests

D.E.I. and S.M. are authors on a patent pending for methods for the generation of kidney glomerular podocytes from pluripotent stem cells (US patent application 14/950859). D.E.I. is a founder, holds equity and chairs the scientific advisory board at Emulate Inc.
} 
Editorial Summary: Donald Ingber and colleagues describe how to generate kidney glomerular podocytes from human iPS cells and how to engineer a human kidney Glomerulus Chip

\section{Abstract}

Tweet: \#NewNProt from Ingber, @geochurch, @ thesamiramusah and colleagues learn how to generate podocytes and build a kidney Glomerulus Chip from human \#iPSCs @ Harvard @WyssInstitute@Harvardmed

\section{Abstract}

Cover Teaser: human iPSC differentiation to kidney podocytes

\section{Keywords}

Podocyte; stem cell differentiation; induced pluripotent stem cell; iPSC; kidney; glomerulus; microfluidic; organ-on-a-chip; in vitro model

\section{INTRODUCTION}

Human pluripotent stem cells, which include embryonic stem (ES) cells ${ }^{1}$ and iPS cells ${ }^{2}$, have expanded the capabilities of cell culture models and their applications in tissue engineering, regenerative medicine, and disease modeling ${ }^{3,4}$. The ability of human iPS cells to self-renew indefinitely and differentiate into many cell types also make them attractive for studying mechanisms of organ development and function. However, development of defined methods for the generation of human kidney cells from iPS cells with specificity and high efficiency has remained elusive. By considering the roles of multiple factors within the cellular microenvironment - including the extracellular matrix and soluble signaling factors - we developed a feeder-free and a serum-free protocol for efficient derivation of kidney glomerular podocytes from both human ES and iPS cells ${ }^{5,6}$. This protocol produces human iPS cell-derived podocytes with greater than $90 \%$ efficiency without genetic manipulations or subpopulation selection during the differentiation procedure, and the resulting cells express lineage-specific markers and exhibit morphological characteristics consistent with the mature phenotype. Additional characterization data based on a global transcriptomic analysis of the human iPS cell-derived podocytes is also presented. Finally, we describe an in vitro method for integrating the iPS cell-derived podocytes into one channel of a 2channel, microfluidic, Organ Chip device along with human glomerular endothelial cells in the second channel to recapitulate the specialized tissue-tissue interface and selective molecular filtration function of the kidney glomerulus.

\section{Development of the Protocol}

There is mounting evidence that multiple factors within the cellular microenvironment can influence cell fate decisions. These include cell interactions with neighboring cells, soluble growth factors, and both mechanical and chemical interactions between cells and the extracellular matrix (ECM) ${ }^{7-15}$. Our strategy was to first identify ECM molecules that could robustly support the adhesion of human iPS cells, as well as their differentiated derivatives, 
as they transition from the pluripotent state to the differentiated podocyte lineage. We examined the expression of cell surface integrin receptors on human iPS cells and an immortalized human podocyte cell line (PCL) (Supplementary Fig. 1, and Supplementary Methods). We found that the integrins $\beta 1$ and $\alpha_{v} \beta_{5}$ were highly expressed on both human iPS cells and the PCL (Supplementary Fig. 1b, c, and d). Given the importance of $\beta 1$ integrins in glomerular development and podocyte function in vivo ${ }^{16,17}$, we used the ECM proteins laminin-511 and Laminin-511-E8 fragment for our differentiation studies as these ligands exhibit strong binding affinity for this integrin receptor subtype ${ }^{18,19}$.

We confirmed that human iPS cells cultured on the laminin-coated surfaces and treated with a medium containing activin A, the small molecule CHIR99021 which activates canonical Wnt signaling ${ }^{20}$, and the Rho-associated kinase (ROCK) inhibitor Y $27632^{10}$ can differentiate into mesoderm cells as indicated by the expression of hand1, goosecoid, and brachyury (Fig. 1-3). By treating the mesoderm cells with an intermediate mesoderminducing medium containing bone morphogenetic protein 7 (BMP7) and CHIR9902120, we obtained cells that express the nephron progenitor cell markers Wilm's tumor 1 (WT1), oddskipped related 1 (OSR1), and paired box gene 2 protein (Pax2). We optimized the timing of the intermediate mesoderm induction and found that all of the human iPS cell (PGP1, IMR-90-1, IISH3i-CB6) and ES cell (H9) lines examined in this study express lineagespecific markers within 16 days of differentiation, and the resulting cells can be expanded in culture for 6-8 weeks or cryopreserved (Fig. 1-2, Box 1 and Box 2).

To induce differentiation into mature, terminally differentiated podocytes, we treated the intermediate mesoderm cells for 4-5 days with a novel medium consisting of BMP7, activin A, vascular endothelial growth factor (VEGF), retinoic acid, and CHIR990215,6 (Fig. 1). Contrary to previous speculations based on the development of kidney organoids ${ }^{21,22}$, and in accordance with in vivo studies on the development of glomerular capillaries ${ }^{23-25}$, we found that induction of the mature differentiated podocyte phenotype does not require supplementation with fibroblast growth factors (FGFs), such as FGF2 or FGF9. By following our differentiation method (Fig. 1-2), we obtained cells that exhibit morphological, molecular, and functional characteristics of mature kidney glomerular podocytes ${ }^{5}$, including the expression of nephrin, podocin and WT1 proteins (Fig. 3c) and the podocyte lineage specification genes SYNPO, PODXL, MAF and EFNB2 with a corresponding decrease in expression of nephron progenitor genes PAX2, SALL1 and EYA1 and the pluripotency genes POU5F1, SOX2, MYC and NANOG (Fig. 4). The human iPS cell-derived podocytes also developed primary and secondary foot processes ${ }^{5}$ (Fig. 3d) similar to those seen in functional kidney glomerular podocytes in vivo ${ }^{26}$. After differentiation, the iPS cell-derived podocytes can be maintained in culture for up to 4 weeks in vitro using a commercially available medium (complete medium kit with CultureBoost-R, Cell Systems Corporation) (Fig. 1).

To develop an in vitro model of the kidney glomerulus, we engineered a 2-channel microfluidic Organ Chip device ${ }^{27,28}$ that recapitulates the tissue-tissue structure, mechanochemical properties, and functional characteristics of a small portion of the human kidney glomerular capillary wall (Figs. 5 and 6, Box 3). The microfluidic device is made from a flexible poly(dimethylsiloxane) (PDMS) elastomer and it contains two parallel 
microchannels $(1 \times 1 \mathrm{~mm}$ top and $1 \times 0.2 \mathrm{~mm}$ bottom channels $)$ separated by a porous flexible PDMS membrane (50 $\mu \mathrm{m}$ thick and $7 \mu \mathrm{m}$ diameter pores with $40 \mu \mathrm{m}$ spacing), as previously described ${ }^{5}$ (Fig. 5). We culture human iPS cell-derived intermediate mesoderm cells in the top channel and differentiate them into podocytes in situ. Primary human glomerular microvascular endothelial cells are seeded on the opposite side of the same porous ECM-coated membrane in the bottom channel to recreate the podocyte-endothelial interface (Fig. 6) where the glomerular basement membrane normally forms in vivo, thereby mimicking the urinary and capillary compartments of a functional kidney glomerulus.

To mimic the dynamic mechanical stretching and relaxation motion observed in living glomeruli in vivo due to the cyclic pulsations of renal blood flow ${ }^{29}$, we included two hollow chambers on each side of the central microfluidic channels and applied cyclic suction $(1 \mathrm{~Hz}$, $-85 \mathrm{kPa})$ to facilitate stretch (10\% strain) and relaxation of the PDMS side walls along with the attached horizontal flexible PDMS membrane with its adherent cell layers. By coculturing human iPS cell-derived podocytes with a layer of primary human kidney glomerular endothelial cells in the microfluidic device, we developed a human kidney Glomerulus Chip that mimics the tissue-tissue interface (Fig. 5a and b) and differential molecular filtration functions of the human glomerular capillary wall, as well as drug (adriamycin)-induced podocyte injury and albuminuria in vitro ${ }^{5}$. Together, our protocol enables the derivation of mature terminally differentiated podocytes from human iPS cells, and their integration into a functional microfluidic device with an adjacent endotheliumlined vascular circuit to recreate the structure, function, and specific drug responses of the living human kidney glomerulus in vitro.

\section{Applications}

The podocyte differentiation protocol has applications in modeling the development and function of the kidney glomerulus, understanding the mechanisms of podocyte injury in glomerulopathies, as well as the establishment of in vitro systems for nephrotoxicity screening and drug discovery. While recent methods in stem cell differentiation have provided insights into the development of nephron progenitor cells ${ }^{30-33}$, the mechanisms underlying podocyte lineage specification and maturation remains largely unknown. This approach can be used to examine the factors that determine cell fate and tissue morphogenetic decisions in terminal differentiation of the kidney glomerulus. Thus, this protocol also provides opportunities for studying both early and late on-set kidney diseases such as congenital nephrotic syndrome (CNS) of the Finnish type and steroid-resistant nephrotic syndrome (SRNS) ${ }^{34,35}$. Mutations in podocyte genes have been implicated in many forms of kidney diseases ${ }^{36-38}$ but animal models often fail to recapitulate human physiological responses ${ }^{3,39}$. This method can therefore be used in combination with genome editing technologies such as CRISPR/Cas $9^{40}$ to produce isogenic human iPS cell lines that differ only by specific mutations and then differentiate them into kidney podocytes to examine disease phenotype and facilitate therapeutic discovery. The microfluidic human kidney Glomerulus Chip advances the capabilities of current tissue culture methods by providing a unique platform to simultaneously investigate the roles of multiple factors on glomerular capillary wall function, including cell-cell interactions, fluid shear stress, and mechanical deformation forces in kidney development and pathophysiology. It also provides 
opportunities to build more complex in vitro structures of the kidney by fluidically linking the Glomerulus Chip to functional microfluidic models of other subunits of the human kidney such as the kidney proximal tubule that have been described previously ${ }^{41,42}$ to study the filtration and reabsorption of molecules, or interconnecting the Glomerulus Chip to other similarly vascularized Organ Chips (e.g., with lung ${ }^{28,43}$, liver ${ }^{3,44-46}$, gut ${ }^{47}$, and bone marrow ${ }^{48}$ ) to develop a human "body-on-a-chip" for physiologically-based prediction of pharmacokinetic/pharmacodynamic parameters in vitro ${ }^{49-51}$. Together, this protocol may be useful for tissue engineering, 3D bioprinting of organs, and regenerative medicine ${ }^{52-55}$. Ultimately, this approach could enable analysis of both hereditary and chronic forms of human kidney disease, as well as facilitate therapeutic development. The methods could also provide an alternative to animal models for studying the pathogenesis of human kidney disease. Because current approaches for propagating primary glomerular podocytes often lead to loss of differentiated phenotype ${ }^{56,57}$, it is possible that the factors we identified for inducing mature podocyte phenotype from human iPS cells could be used to improve cell culture methods for primary tissues isolated from human kidney. Finally, cell-based therapy for human kidney glomerular tissue has remained largely unexplored due to several factors including the lack of functional human kidney glomerular podocytes as well as a method to precisely deliver these cells to injured glomerular capillaries. We hypothesize that it also may be possible to use the human iPS cell-derived podocytes as an injectable form of cell therapy for treatment of diseases that are characterized by podocyte loss or dysfunction.

\section{Comparison with other methods}

Our differentiation protocol is specific for the derivation of only one type of human kidney cell - mature podocytes - with extremely high (>90\%) efficiency. Other stem cell differentiation strategies, such as those used previously to generate kidney organoids ${ }^{21,22,32}$, produce mixed population of cells and therefore require additional optimization strategies to guide lineage specification into podocytes. This limits their application where pure populations of podocytes are desired, such as in injectable cell-based therapies, targeted drug screening, or developing tissue-specific models of glomerular function as we do here by using Organ Chip technology. It also remains unclear whether the podocyte-like cells produced by kidney organoid cultures can be isolated, maintained in culture, or used for applications in different experimental systems without loss of cell phenotype and functionality, as this frequently occurs in primary cultures of kidney podocytes ${ }^{57,58}$. In contrast, we demonstrate high levels of differentiation and functionality in our model, independent of genetic manipulation or subpopulation selection, which has not been achieved previously.

Another method that has been previously used to differentiate human iPS cells into podocytes involved the formation of embryoid bodies (EBs) in serum-containing medium ${ }^{59}$. As with organoids, the inherent heterogeneity of EBs results in a very low $(<1 \%)$ yield of podocyte-like cells with immature phenotype which limits their utility in applications where a specific cell type (such as neurons or podocytes) are desired. In contrast, our method produces $>90 \%$ of cells with morphological and molecular phenotype associated with mature glomerular podocytes. Additionally, the use of serum components and poorly defined animal-derived ECM such as Matrigel and Geltrex in previous reports ${ }^{59,60}$ makes it unclear 
as to which signaling components contribute specifically to the differentiation of human kidney podocytes. Our protocol employs defined soluble signaling factors and ECM proteins that bind to specific cell surface integrins and robustly support the adhesion and induction of podocyte lineage from human iPS cells. Our protocol may therefore be better suited for studying the molecular mechanisms of podocyte development and lineage specification.

We induced the differentiation of human iPS cell-derived podocytes in our microfluidic Organ Chip device, which is not possible with previously published methods. We also engineered a functional in vitro model of the human kidney glomerular capillary wall by coculturing the iP cell-derived podocytes with a layer of primary human glomerular endothelial cells to form a functional endothelium-lined vasculature as required for glomerular filtration studies. Our microfluidic model of the glomerular capillary wall also recapitulates the tissue-tissue structure and partitioning of the urinary and vascular compartments of living glomeruli and enables the filtration of molecules such as inulin from the vascular channel into the urinary space while retaining albumin in the vasculature, much as expected in a functional human kidney glomerulus. Our microfluidic human kidney Glomerulus Chip also serves as a useful platform for studying the role of mechanical forces on glomerular development as we demonstrated by uncovering a role for mechanical strain on podocyte differentiation and differential deposition of GBM component, Collagen IV, by podocytes and endothelial cells ${ }^{5}$. These could not be accomplished using traditional cell culture models or organoids as they lack the tissue structure and endothelium-lined vascular circuit necessary for kidney glomerular filtration studies.

\section{Limitations}

Our differentiation method worked well for all the human ES (H9) and iPS (PGP1, IISH3iCB6, and IMR-90-1) cell lines examined in this study. Due to intrinsic variability in human iPS and ES cell lines ${ }^{61}$, however, researchers may need to adjust the protocol depending on the cell line they are using. Some of the modifications may include the use of different concentrations of the signaling factors, the timing of induction for each stage of differentiation, and the type of cell culture substrate or ECM component. The overall timing of our protocol is adequate for creation of the Glomerulus Chip, and given that it typically takes several months to obtain functional cell types such as motor neurons ${ }^{62}$ and astrocytes ${ }^{63}$ from human iPS and ES cell lines, the derivation of mature glomerular podocytes in $<30$ days is considerably rapid. Still, a faster protocol may be desired in some situations, and it is conceivable that the pathways targeted by the signaling factors that we have identified for lineage specification of kidney podocytes could inform future studies focused on the establishment of more rapid methods for podocyte differentiation using technologies such as transcriptional activation ${ }^{64,65}$ and mechanotransduction ${ }^{13,14,66,67}$, in a synergistic or independent manner.

Clinical applications of the human iPS cell-derived podocytes may also require differentiation on a larger scale. While differentiation of human podocytes at industrial scale was not the goal of this work, we achieved podocyte differentiation in both the microfluidic Organ Chip device (to model glomerular development and function in a multiplexed 
manner), and in standard tissue culture plates which should enable podocyte differentiation at a larger scale in the future.

Our microfluidic kidney Glomerulus Chip device also has some limitations. First, the PDMS material used in the fabrication of our model may absorb small hydrophobic molecules which could compromise their utility in measuring the toxicity and efficacy of certain drugs. However, we and others have identified elastomers ${ }^{68,69}$ that do not absorb small molecules and could potentially be used as alternatives to PDMS for engineering microfluidic Organ Chips. It is also possible to use analytical techniques such as mass spectrometry to examine the real dose of drugs within the microfluidic devices for more accurate detection of effective concentrations. With these PDMS drug absorption data in hand, it is then possible to carry out pharmacokinetic modeling using these types of Organ Chips ${ }^{51}$. The flexible PDMS membrane with engineered pores is also thicker $(50 \mu \mathrm{m})$ than the GBM in vivo which is usually less than $1 \mu \mathrm{m}$ thick $^{70}$, and it lacks the curvature of glomerular capillaries. These differences are primarily due to technical challenges in engineering thin sheets of PDMS with optimal structural integrity and ease of handling. Although we achieved retention of albumin in the vascular channel and excretion of inulin across the glomerular filtration barrier, the $7 \mu \mathrm{m}$ diameter pores of the engineered membrane are large and allow large proteins to enter the urinary channel if cells are seeded sparsely, and thus cultures must be confluent before studies can be initiated. We found that the human iPS cell-derived podocytes and primary endothelial cells used in the microfluidic device can produce GBM components including collagen IV ${ }^{5}$ and laminin (data not shown) which could potentially form a more physiologically relevant barrier between the two cell layers. Results of control studies also showed that acellular chips, or chips lined by endothelium alone or by irrelevant cell types, such as fibroblasts and renal proximal tubule epithelial cells (all coated with similar ECM), fail to recapitulate the selective filtration of the Glomerulus Chip. Thus, our results could not be explained simply by differences in diffusion coefficients alone. In the future, it might be possible to engineer the microfluidic device such that it comprises a porous membrane made with degradable ECM molecules ${ }^{71}$ which would allow the cells to further remodel the basement membrane it forms and produces a barrier that more closely resemble the GBM in vivo. This could also help overcome some of the technical challenges associated with the processing of cell-lined PDMS materials for end-point analyses by transmission electron microscopy and scanning electron microscopy, which may be necessary to visualize podocyte foot process development and interdigitating networks.

Finally, while the Glomerulus Chip recapitulates many of the key functions of the glomerular capillary wall, it does not mimic all the functionalities of a whole kidney glomerulus. For example, our microfluidic device contains only a subset of cells compared to a whole living glomerulus. The fluid flow rate $(60 \mu \mathrm{L} / \mathrm{hr})$ and shear stresses $(0.0007$ and $0.017 \mathrm{dyn} / \mathrm{cm}^{2}$ ) in the urinary and vascular channels, respectively, are also lower than those observed in vivo. Overcoming this problem may require the use of large volume of medium per experiment which may not be practical for most laboratory settings. It is also possible to modify the experimental setup to enable fluid recirculation at higher flow rates or employ pressure-driven flow of smaller volumes of cell culture media. 


\section{MATERIALS \\ REAGENTS}

Cells-! CAUTION The cell lines in your research should be regularly tested to ensure that they are karyotypically normal and not contaminated by mycoplasma. All cell lines mentioned in this protocol were tested for mycoplasma contamination before use.

- Human iPS cells or ES cells. This protocol can be performed on any human iPS or ES cell line. We used PGP1 (The Personal Genome Project and Church Laboratory at Harvard Medical School), IISH3i-CB6 (WiCell Research Institute, lot. no. DB0005 ), IMR-90-1 (WiCell Research Institute, lot. no. iPS(IMR90)-1DL-01), and H9 (WA09, WiCell Research Institute, lot. no. RB40917). !

CAUTION The use of human iPS and ES cells require adherence to appropriate national laws and institutional regulatory board and funding agency guidelines. All cell lines were obtained under appropriate material transfer agreement and approved by the institutional review board (IRB) and institutional embryonic stem cell research oversight (ESCRO) committee at Harvard University.

- Conditionally immortalized human podocyte cell line (Mundel laboratory at Massachusetts General Hospital and Harvard Medical School)

- $\quad$ Primary human glomerular microvascular endothelial cells (Cell Systems, cat. no. ACBRI $128 \mathrm{~V}$ )

\section{Growth factors and media supplements}

- $\quad$ mTeSR medium (Stem Cell Technologies, cat. no. 05850)

- $\quad$ DMEM/F12 (Thermo/Life Technologies, cat. no. 12634028)

- $\quad$ DMEM/F12 with GlutaMAX supplement (Thermo/Life Technologies, cat. no. 10565042)

- $\quad$ Complete serum-free medium kit with recombinant proteins and CultureBoost-R (SF-4Z0-500-R)

- $\quad$ Complete medium kit with CultureBoost-R (Cell Systems Corp., 4Z0-500-R)

- Human Activin A (Thermo/Life Technologies, cat. no. PHC9564)

- $\quad$ Human BMP7 ((Thermo/Life Technologies, cat. no. PHC9544)

- $\quad$ Human VEGF (Thermo/Life Technologies, cat. no. PHC9394)

- $\quad$ B27 serum-free supplement (Thermo/Life Technologies, cat. no. 17504044)

- $\quad$ Y27632 ROCK inhibitor (Tocris, cat. no. 1254)

- CHIR99021, 2 mg (STEMGENT, cat. no. 04-0004) CRITICAL We have observed differences in the quality of cells cultured with CHIR99021 compound from different suppliers or manufacturers. We therefore recommend lot testing especially for compounds purchased elsewhere.

- All-trans retinoic acid, $500 \mathrm{mg}$ (Stem Cell Technologies, cat. no. 72262) 
- Heat inactivated fetal bovine serum (FBS) (Thermo/Life Technologies, cat. no. 10082147)

- $\quad$ Penicillin-Streptomycin, liquid (100X) (Thermo/Life Technologies, cat. no. 15140-163)

\section{Antibodies and fluorescent stains}

- $\quad$ Oct4 (R\&D Systems, cat. no. AF1759)

- $\quad$ TRA-1-60 (Abcam, cat. no. ab16288)

- $\quad$ Goosecoid (R\&D Systems, cat. no. AF4086)

- $\quad$ Brachyury (Abcam, cat. no. ab20680)

- $\quad$ HAND1 (Abcam, cat. no. ab196622)

- $\quad$ Pax2 (Invitrogen, cat. no. 71-6000)

- $\quad$ OSR1 (Novus Biologicals, cat. no. H00130497-M04

- $\quad$ WT1 (Millipore, cat. no. MAB4234)

- $\quad$ Nephrin (Progen, cat. no. GP-N2)

- $\quad$ Podocin (Abcam, cat. no. ab50339)

- $\quad$ VE-cadherin (Santa Cruz Biotech, cat. no. sc-9989)

- $\quad$ Collagen type IV (Abcam, cat. no. ab6586)

- $\quad$ Integrin $\beta 1$ (Abcam, cat. no. ab24693)

- ApoL1, anti-apolipoprotein L1 (Abcam, cat. no. ab85795)

- $\quad 4^{\prime}, 6$-diamidino-2-phenylindole (DAPI) (Thermo/Life Technologies, cat. no. D1306)

- $\quad$ Oct4 conjugated to phycoerythrin (Oct4-PE) (Stem Cell Technologies, cat. no. 60093PE)

- $\quad$ Alexa Fluor 488 and Alexa Fluor 594-conjucated secondary antibodies ((Thermo/Life Technologies)

- WTI conjugated to APC (WT1-APC) (LifeSpan Biosciences, cat. no. LSC224662/5744)

- Nephrin conjugated to PE-Cy5 (Nephrin-PE-Cy5) (Bioss, cat. no. bs-10233RPE-Cy5)

\section{ECM molecules}

- $\quad$ Matrigel hESC-qualified matric, $5 \mathrm{~mL}$ vial (BD Biosciences, cat. no. 354277). This reagent shows lot-to-lot variation. Lot testing for successful human iPS and ES cell culture is recommended. Keep Matrigel cold and use manufacturer recommended dilution factor for iPS or ES cell culture. 
- $\quad$ iMatrix-511 Laminin-E8 (LM-E8) fragment (Iwai North America Inc., cat. no. N-892012)

- Human recombinant Laminin 511 protein (Biolamina, cat. no. LN511-02)

\section{Enzymes and other reagents}

- $\quad$ Accutase (Thermo/Life Technologies, cat. no. A1110501)

- $\quad$ Enzyme-free cell dissociation buffer, Hank's balanced salt (Thermo/Life Technologies, cat. no. 13150016)

- $\quad$ Trpsin-EDTA 0.05\% (Thermo/Life Technologies, cat. no. 25300-120)

- $\quad$ MycoAlert Mycoplasma Detection Kit (Lonza, cat. no. LT07-318)

- $\quad$ Phosphate Buffered Saline (PBS) (Thermo/Life Technologies, cat. no. 14190250)

- $\quad$ PBS with calcium and magnesium (Thermo/Life Technologies, cat. no. 14040182)

- $\quad$ Saponin (Sigma-Aldrich, cat. no. 47036)

- $\quad$ Triton X-100 (VWR, cat. no. 97062-208)

- $\quad$ Bovine serum albumin (BSA) (Sigma-Aldrich, cat. no. A9418)

- $\quad$ Paraformaldehyde (Thermo/Life Technologies, cat. no.28906) ! CAUTION PFA should be handled in a chemical fume hood with proper personal protection equipment including gloves, lab coat, and safety eye glasses. Avoid inhalation and contact with skin.

- $\quad$ Dimethyl sulfoxide (DMSO) (Sigma-Aldrich, cat. no. D2438) ! CAUTION DMSO is toxic and should be handled in chemical safety hood by using personal protection equipment.

- $\quad$ Cell counting kit 8 (CCK-8) (Dojindo, cat. no. CK04-01)

- $\quad$ Inulin-FITC (Sigma-Aldrich, cat. no. F3272)

- $\quad$ Human albumin conjugated to TexasRed (Rockland, cat. no. 009-0933)

\section{Tissue culture and microengineering supplies}

- $\quad$ T25 flask with canted vented cap (Corning Inc., cat. no. 353108)

- $\quad$ Filter system $0.22 \mu \mathrm{m}$ PES 500mL (Corning Inc., cat. no. 431097)

- $\quad$ Steriflip $0.22 \mu \mathrm{m}$ PES (EMD Millipore, cat. no. SCGP00525)

- $\quad$ Tissue culture treated 6-well plates (Corning Inc., cat. no. 353046)

- $\quad$ Tissue culture treated 12-well plates (Corning Inc., cat. no. 353043)

- $\quad$ Falcom $150 \mathrm{~mm}$ cell culture dish (Corning Inc., cat. No. 353025)

- $\quad$ Wide beveled cell lifter (Corning Inc., cat. no. 3008) 
- $\quad$ Cryogenic vial rack and tray (Corning Inc., cat. no. 430525)

- $\quad$ Conical centrifuge tube, $15 \mathrm{~mL}$ (Corning Inc., cat. no. 352097)

- $\quad$ Conical centrifuge tube, $50 \mathrm{~mL}$ (Corning Inc., cat. no. 352098)

- $\quad$ CryoTube vials (NUNC Inc., cat. no. 377267)

- $\quad$ Aspirating pipettes, individually wrapped (Corning Inc., cat. no. 29442-462)

- $\quad$ P10 precision barrier pipette tips (Denville Scientific, cat. no. P1096-FR)

- $\quad$ P20 barrier pipette tips (Denville Scientific, cat. no. P1121)

- $\quad$ P100 barrier pipette tips (Denville Scientific, cat. no. P1125)

- $\quad$ P200 barrier pipette tips (Denville Scientific, cat. no. P1122)

- $\quad$ P1000 barrier pipette tips (Denville Scientific, cat. no. P1126)

- $\quad$ Serological pipette, $5 \mathrm{~mL}$, individually wrapped (Corning Inc., cat. no. 356543)

- $\quad$ Serological pipette, $10 \mathrm{~mL}$, individually wrapped (Corning Inc., cat. no. 356551)

- $\quad$ Serological pipette, $25 \mathrm{~mL}$, individually wrapped (Corning Inc., cat. no. 356525)

- $\quad$ Stainless steel disposable safety scalpels (Integra Miltrex, cat. no. 4-510)

- $\quad$ Kim wipes, small (VWR, cat. no. 21905-026)

- $\quad$ Kim wipes, large (VWR, cat. no. 21905-049)

- $\quad$ Kimberly-Clark nitrile gloves, long cuff (VWR, cat. no. 50601)

- $\quad$ Kimber-Clark basic plus lab coat (VWR, cat. no. 37000-922)

- $\quad$ Tyvek isoclean sleeves (VWR, cat. no. 89127-350)

- $\quad$ Ethanol solution, 70\% (v/v), biotechnology grade (VWR, cat. no. 97065-058) ! CAUTION Ethanol is toxic and flammable. Use personal protection equipment for handling.

\section{Microengineering and microfluidic cell culture supplies.}

- $\quad$ Poly(dimethylsiloxane) (PDMS; Sylgard 184 Silicone Elastomer Kit; Dow Corning, cat. no. 3097358-1004)

- $\quad$ Prototherm 12120 using stereolithography (Proto Labs)

- $\quad$ Blunt needles (18 gauge; VWR, cat. no. KT868280)

- $\quad$ Silicone tubing (Saint-Gobain Tygon sanitary tubing, inner diameter $=1 / 32$ inches; Fisher Scientific, cat. no. 02-587-1a)

- $\quad$ 2-Stop PharMed BPT tubing with ID: $0.25 \mathrm{~mm}$ diameter (Cole-Parmer, cat. No. EW-95713-12)

- $\quad$ PharMed BPT extension tubing, $0.25 \mathrm{~mm}$ diameter (Cole-Parmer, cat. No. EW-95809-12) 
- Dakin fully frosted microscope slide glass, $25 \times 75 \times 1 \mathrm{~mm}$ (Thermo Scientific, cat. no. 50-949-382)

- $\quad$ Blunt needles (18 gauge; VWR, cat. no. KT868280)

- $\quad$ Disposable $5 \mathrm{~mL}$ syringes with luer-lok tips (BD Bioscience, cat. no. 309646)

- $\quad$ Y-connectors (Cole-Parmer, cat. no. 30703-90)

- $\quad$ Silicon wafers $(50 \times 50 \mathrm{~mm}$; University Wafer $)$

- $\quad$ Tweezers (SPI Supplies, cat. no. 2WFG.SA)

\section{EQUIPMENT}

- $\quad$ Biosafety cabinet, Series 1300 Type A2 (ThermoFisher, cat. No. 1333)

- $\quad \mathrm{CO}_{2}$ Incubator, Forma Steri-Cycle $\mathrm{CO}_{2}$ Incubators (ThermoFisher, cat. No. 201370)

- $\quad$ Light microscope, Nikon EclipseTS100-F microscope equipped with a Zeiss AxioCam MRc 5

- Hemacytometer chamber with cover glass (VWR, cat. no. 15170-172)

- $\quad$ Epifluorescence microscope, Zeiss Axio Observer Z1 microscope equipped with a Cool Snap HQ2 camera and Carl Zeiss Zen software

- $\quad$ Confocal microscope, Leica SP5 X MP inverted microscope with a 25×/0.95 water objective.

- $\quad$ Plate reader, Synergy NEO HTS Multi Mode microplate reader (BioTek Instruments, cat. No. 12817142)

- $\quad$ Balance (Mettler Toledo, cat. no. XS204)

- $\quad$ Dual chamber dry oven (FinePCR, cat. no. combi-D24)

- $\quad$ PlasmaEtcher (Plasma Etch, cat. No. PE- 100)

- $\quad$ Peristaltic pump, Ismatec low-speed planetary gear-driven peristaltic pump with 16 channels (Cole-Parmer, cat. No. EW- 78001-30)

- $\quad$ Programable Vacuum regulator system. Our vacumm regulator was built inhouse and it consists of a vacuum regulator (SMC Corporation of America, cat. no. ITV0091-2BL) that was electronically controlled by an Arduino Leonardo and MAX517 digital to analogue converter. The regulator outputs a sinusoidal vacuum profile with a user-defined amplitude and frequency.

- $\quad$ Centrifuge, 5810R Benchtop Centrifuge (Eppendorf, cat. No. 022625501)

- $\quad$ Flow cytometer, LSRFortessa (BD Biosciences, cat. No. 647465) 


\section{REAGENT SETUP}

\section{Human pluripotent stem cells.}

Before initiating differentiation, the human iPS or ES cells should be adapted to feeder-free culture systems with mTeSR medium in Matrigel-coated plates. We use human iPS and ES cells at $\sim 70 \%$ confluency (around 4 days after passaging) for differentiation experiments.

\section{Defined mTeSR medium.}

Combine basal medium and supplement to make a 500-mL stock. Prepare $45 \mathrm{~mL}$ aliquots into $50 \mathrm{~mL}$ conical tubes and store at $-20^{\circ} \mathrm{C}$ for up to six months. Thaw aliquots in refrigerator overnight and use within two weeks.

\section{Matrigel.}

It is essential that all items that come in contact with Matrigel are kept cold to prevent it from polymerizing at room temperature $\left(20-25^{\circ} \mathrm{C}\right)$. To thaw Matrigel, place on ice and keep refrigerated overnight. Prepare aliquots on ice according to the dilution factor provided by the manufacturer for each lot. Store aliquots at $-20^{\circ} \mathrm{C}$ until ready to use, and no longer than the expiration date indicated by the manufacturer.

\section{Matrigel-coated plates.}

Dilute appropriate amount of Matrigel in $25 \mathrm{~mL}$ of cold DMEM/F12 in a $50-\mathrm{mL}$ conical tube and mix well. Add $1 \mathrm{~mL}$ of Matrigel to each well of a 6-well plate and incubate at $37^{\circ} \mathrm{C}$ for two hours or at $4^{\circ} \mathrm{C}$ for a minimum of 24 hours. Coated plates can be used immediately or stored at $4^{\circ} \mathrm{C}$ for up to two weeks.

\section{Laminin 511-E8-coated plates.}

All 2D differentiation steps were carried out in 12-well plates. For each 12-well plate, dilute appropriate amount of laminin 511-E8 in $9 \mathrm{~mL}$ of sterile distilled water to achieve a concentration of $5 \mu \mathrm{g} / \mathrm{mL}$. Coat plates by adding $700 \mu \mathrm{L}$ per well and incubate for 2 hours at room temperature or refrigerate at $4^{\circ} \mathrm{C}$ overnight. The laminin 511-E8-coated plate can be stored for up to a week at $4^{\circ} \mathrm{C}$.

\section{Activin A.}

Reconstitute in sterile PBS with $0.1 \%$ (wt $/ \mathrm{v}$ ) BSA to make $100 \mu \mathrm{g} / \mathrm{mL}$ stock. Prepare working aliquots (e.g. $100 \mu \mathrm{L}$ ) and store at $-20^{\circ} \mathrm{C}$ for up to six months and avoid freezethaw cycles.

BMP7.

Reconstitute in sterile distilled water containing $0.1 \%$ (wt/v) BSA to make $100 \mu \mathrm{g} / \mathrm{mL}$ stock. Prepare working aliquots (e.g. $100 \mu \mathrm{L}$ ) and store at $-20^{\circ} \mathrm{C}$ for up to six months and avoid freeze-thaw cycles. 
VEGF.

Reconstitute in sterile PBS with $0.1 \%$ (wt/v) BSA to make $100 \mu \mathrm{g} / \mathrm{mL}$ stocks. Prepare working aliquots (e.g. $100 \mu \mathrm{L}$ ) and store at $-20^{\circ} \mathrm{C}$ for up to six months and avoid freezethaw cycles.

CHIR99021.

Prepare a $30 \mathrm{mM}$ stock solution by dissolving $2 \mathrm{mg}$ of CHIR99021 in $143.3 \mu \mathrm{L}$ of sterile DMSO. Make working aliquots (e.g. $5 \mu \mathrm{L}$ ) and store at $-20^{\circ} \mathrm{C}$ for up to a month.

Y27632.

Dissolve $10 \mathrm{mg}$ of Y27632 in $3.079 \mathrm{~mL}$ of sterile distilled water to obtain a $10 \mathrm{mM}$ stock solution. Prepare working aliquots (e.g. $100 \mu \mathrm{L}$ ) and store at $-20^{\circ} \mathrm{C}$ for up to six months.

\section{All-trans retinoic acid.}

Prepare $10 \mathrm{mM}$ stock solution by dissolving $10 \mathrm{mg}$ in $3.33 \mathrm{~mL}$ of sterile DMSO. Aliquot into working volumes (e.g. $500 \mu \mathrm{L}$ ) and store protected from light at $-20^{\circ} \mathrm{C}$ for up to six months.

\section{Complete medium with CultureBoost-R.}

Prepare stock by adding CultureBoost-R supplemenat to basal medium per manufacture guidelines. Store at $4^{\circ} \mathrm{C}$ and use within two weeks.

\section{Mesoderm differentiation medium.}

Prepare medium fresh consisting of DMEM/12 with GlutaMax, $100 \mathrm{ng} / \mathrm{mL}$ Activin A, $3 \mu \mathrm{M}$ CHIR99021, $10 \mu \mathrm{M}$ Y27632, and 1X B27 serume-free supplement. As an option, 1\% (v/v) of Penicillin-Streptomycin may be added, in which case the volume of DMEM/12 with GlutaMax should be adjusted accordingly. Prepare medium at a volume suitable for the scale of the experiment. We typically prepare $50 \mathrm{~mL}$ of medium for experiments with two 12 -well plates.

\section{Intermediate mesoderm differentiation medium.}

Make medium consisting of DMEM/12 with GlutaMax, $100 \mathrm{ng} / \mathrm{mL}$ BMP7, $3 \mu \mathrm{M}$ CHIR99021, and 1X B27 serume-free supplement. An optional 1\% (v/v) of PenicillinStreptomycin may be added, in which case the volume of DMEM/12 with GlutaMax should be adjusted accordingly. This medium may be prepared in a large batch (e.g. $500 \mathrm{~mL}$ ) and aliquoted into $50 \mathrm{~mL}$ working volumes and stored at $-20^{\circ} \mathrm{C}$ for up to three months. Frozen aliquots can be thawed overnight at $4^{\circ} \mathrm{C}$ before use.

\section{Podocyte induction medium.}

Prepare induction medium consisting of DMEM/F12 with GlutaMax supplemented with 100 ng/mL BMP7, 100 ng/mL Activin A, 50 n/mL VEGF, $3 \mu$ M CHIR99021, 1× B27 serumfree supplement, and $0.1 \mu \mathrm{M}$ all-trans retinoic acid. An optional 1\% (v/v) of PenicillinStreptomycin may be added, in which case the volume of DMEM/12 with GlutaMax should be adjusted accordingly. It is crucial that this medium is protected from light. The medium 
may be prepared in a large batch (e.g. $500 \mathrm{~mL}$ ) and aliquoted into $12 \mathrm{~mL}$ working volumes and stored protected from light at $-20^{\circ} \mathrm{C}$ for up to three months. Thaw frozen aliquots overnight at $4^{\circ} \mathrm{C}$ before use.

\section{Trypsin neutralizing solution.}

Freshly prepare a solution consisting of DMEM/F12 with GlutaMax and 10\% (v/v) FBS. Filter the medium by using a filter system or Steriflip.

\section{Laminin 511-coated chips.}

Dilute laminin 511 protein in sterile PBS containing calcium and magnesium to obtain a 50 $\mu \mathrm{g} / \mathrm{mL}$ solution. A solution of $500 \mu \mathrm{L}$ is sufficient for an experiment. with 10 microfluidic chips. Fill both channels of the microfluidic device with the freshly prepared solution and incubate the chips overnight at $37^{\circ} \mathrm{C}$. ECM-coated chips should be used within $24 \mathrm{hr}$. Prior to cell seeding, gently remove the ECM solution by pipetting and rinse chips three times with pre-warmed DMEM/F12.

\section{Permeabilization buffer.}

Prepare a solution consisting of $0.125 \%$ (v/v) triton X-100 in PBS. This solution can be prepared in a large batch (e.g. $500 \mathrm{~mL}$ ) and stored at room temperature for up to a month.

\section{PROCEDURE}

CRITICAL We have optimized multiple parameters in this differentiation protocol, including the type of ECM used, soluble factors and their concentrations, timing of differentiation, and the frequency of medium change. We strongly recommend that researchers follow this protocol as described.

\section{Maintenance of human iPS cells in feeder-free culture with mTeSR medium. TIMING $\sim 7 \mathrm{~d}$ \\ CRITICAL All iPS cell maintenance culture described here use defined mTeSR medium and six-well tissue culture-treated plates coated with human ES cell-qualified Matrigel.}

1. Prior to passaging, inspect the condition of iPS cell cultures and identify if there are spontaneously differentiated cells. Good undifferentiated iPS cells exhibit round colony morphology with defined boundary. Some merged colonies are acceptable, especially for feeder-free culture conditions. Proceed to the next step when iPS cell colonies are about 70-80\% confluent.

2. Prepare Matrigel solution (see Reagent Setup).

3. Coat a six-well plate with $1 \mathrm{~mL} /$ well of Matrigel (see Reagent Setup).

4. Aspirate Matrigel from plates and rinse three times with prewarmed DMEM/F12.

5. Aspirate used mTeSR medium from human iPS cells and rinse the cells twice with DMEM/F12. Add $1 \mathrm{ml}$ of Accutase to each well and incubate at $37^{\circ} \mathrm{C}$ for 1 min or until the edges of the colonies begin to roll up or loosen. Perform a visual check and aspirate Accutase. ! CAUTION. It is important to not expose iPS cells to Accutase for too long as this could lead to complete dissociation and loss of 
the cells during aspiration. Timing may vary depending on iPS cell density or cell line. For all cell lines used in this study, 1-2 min was sufficient to achieve cell dissociation.

\section{TROUBLESHOOTING}

6. Add $3 \mathrm{~mL}$ of mTeSR to each well and gently scrape the cells off using a cell lifter.

7. Pipette several times to obtain cell suspension with small clumps. Add $0.5 \mathrm{ml}$ of the iPS cell suspension to each well of the newly prepared Matrigel-coated sixwell plates. Add an additional $2 \mathrm{~mL}$ of mTeSR medium to each well and shake the plates gently to distribute the cells.

8. Maintain the iPS cells at $37^{\circ} \mathrm{C}$ in a $5 \% \mathrm{CO}_{2}$ incubator. Replace the medium daily.

9. Passage cells approximately every 6 days or when they reach about $80 \%$ confluency.

\section{Preparation of human iPS cells for differentiation. TIMING $\sim \mathbf{4} \mathbf{d}$}

CRITICAL We recommend starting all differentiation studies with iPS cell cultures that are in the mitotic phase. This is typically achieved when human iPS cells are within the first 4 days of passaging or when the cells are no more than $80 \%$ confluent. We use cells after 3-4 days of passaging and at a maximum of about $70 \%$ confluence.

10. Perform visual inspection of the iPS cells colonies that have been cultured for $3-$ 4 days after passaging and are about $70 \%$ confluent, to make sure that there are no spontaneously differentiated cells. If necessary, remove differentiated cells by scraping or aspiration under sterile conditions. Add $2 \mathrm{~mL}$ of mTeSR medium to each well and place the cells at $37^{\circ} \mathrm{C}$ in a $5 \% \mathrm{CO}_{2}$ incubator until needed for mesoderm differentiation as described below.

\section{Differentiation of human iPS cells into mesoderm cells. TIMING $2 \mathrm{~d}$}

11. Prepare laminin 511-E8-coated plates (see Reagent Setup).

12. Prepare mesoderm induction medium (see Reagent Setup).

13. Working in a biosafety cabinet and under sterile conditions, aspirate mTeSR medium from iPS cells cultured on Matrigel-coated plates (step 10). Rinse the cells three times with pre-warmed DMEM/F12.

14. Dissociate the iPS cells by incubating them with enzyme-free cell dissociation buffer $\left(1 \mathrm{~mL}\right.$ per well of a six-well plate) for approximately $10 \mathrm{~min}$ in a $37^{\circ} \mathrm{C}$ incubator. Timing may depend on the density of iPS cell colonies as well as the cell line. Visually inspect iPS cells to ensure that the colonies are dissociated. It is normal to have some floating cells.

15. Using a cell lifter, gently scrape cells and pipette cell suspension into a conical tube. For example, transfer up to two wells of dissociated iPS cells into a $15 \mathrm{~mL}$ conical tube. Pipette cells few times to individualize the iPS cells. Bring conical 
tube up to $15 \mathrm{ml}$ volume by using pre-warmed DMEM/F12 and centrifuge cells for $5 \mathrm{~min}$ at $290 \mathrm{xg}(1200 \mathrm{rpm})$ at room temperature $\left(20-23^{\circ} \mathrm{C}\right)$. Remove supernatant and resuspend cells again in pre-warmed DMEM/F12 for another round of centrifugation under the same conditions. The second round of centrifugation should minimize the retention of residual components such as Matrigel (from scraping the plates) and cell dissociation reagent in the final cell suspension for seeding on the plates coated with the defined laminin 511-E8.

16. Aspirate supernatant and resuspend cells first in a small volume (about $1 \mathrm{~mL}$ ) of the mesoderm induction medium. Using a hemocytometer or other cell counting device, determine the number of cells and add appropriate volume of the mesoderm induction medium to achieve a concentration of $\sim 10 \times 10^{4}$ cells per $\mathrm{mL}$.

17. Aspirate ECM solution from the newly prepared laminin 511-E8-coated plates (step 11) and rinse the plates twice with DMEM/F12. Remove residual $\mathrm{DMEM} / \mathrm{F} 12$ before adding cell suspension.

18. Mix iPS cell suspension well by pipetting a few times and then transfer $1 \mathrm{~mL}$ of the cell suspension to each well of a 12-well plate coated with laminin 511-E8. Shake the plate gently to distribute the cells and incubate at $37^{\circ} \mathrm{C}$ in a $5 \% \mathrm{CO}_{2}$ incubator.

19. Refresh medium the next day.

20. Culture cells for 2 days of differentiation, after which the human iPS-derived mesoderm cells should be ready for intermediate mesoderm induction as described below.

\section{TROUBLESHOOTING}

\section{Differentiation of human iPS cell-derived mesoderm into intermediate mesoderm cells. TIMING minimum of $14 \mathrm{~d}$}

21. Prepare intermediate mesoderm differentiation medium (see Reagent Setup).

22. Aspirate the medium from the mesoderm cells and incubate with pre-warmed intermediate mesoderm differentiation medium at $1 \mathrm{~mL}$ per well of a 12-well plate.

23. Refresh medium daily. CRITICAL STEP It is important that the medium is refreshed daily as the cells are metabolically active and quickly deplete the growth factors and supplements. If the medium becomes too acidic (typically yellow in appearance), increase the volume of the medium (for example, $1.3 \mathrm{~mL}$ per well of a 12-well plate). Some researchers may wish to experiment with growth factors that are packaged for controlled release into the cell culture medium, but this will need to be tested for feasibility and effectiveness on the differentiation of each iPS cell line.

24. TROUBLESHOOTING Culture cells for 14 days to reach intermediate mesoderm differentiation. Follow Box 1 for a detailed protocol for passaging of 
the human iPS cell-derived intermediate mesoderm cells for up to one month or see Box 2 for a protocol for cryopreservation of human iPS cell-derived intermediate mesoderm cells. If you are planning to use these cells to generate podocytes in an organ-on-a-chip microfluidic device, follow box 3 to make and prepare the chip for cell culture 5 days prior to cells reaching intermediate mesoderm differentiation.

25. To generate podocytes using tissue culture plates follow option A or to generate podocytes using organ-on-a-chip microfluidic follow option B.

\section{TROUBLESHOOTING}

\section{Option A Derivation of mature kidney podocytes using laminin-coated tissue culture plates TIMING 4-5 d}

i. $\quad$ Prepare a new laminin 511-E8-coated plate (see Reagent Setup).

ii. Prepare podocyte induction medium (see Reagent Setup) at a volume suitable for the scale of your experiment. $50 \mathrm{~mL}$ of the podocyte induction medium is sufficient for an experiment using a 12-well plate. CRITICAL STEP It is important to protect this medium from light. The tube/bottle containing the podocyte induction medium can be wrapped with foil paper during pre-warming, handling, and storage.

iii. Prepare $25 \mathrm{~mL}$ of Trypsin neutralizing solution (see Reagent Setup) for each 12well plate.

iv. Rinse intermediate mesoderm cells three times with pre-warmed DMEM/F12.

v. Dissociate cells by incubating them with $0.05 \%$ Trypsin-EDTA at $0.5 \mathrm{~mL}$ per well of a 12-well plate for about $3 \mathrm{~min}$ at $37^{\circ} \mathrm{C}$. Timing will depend on cell density and the human iPS cell line used. We typically passage the intermediate mesoderm cells when they are at about 100\% confluent, and approximately 3 min of incubation with Trypsin was sufficient for dissociation of cells derived from all of the human iPS and ES cell lines used in this study.

vi. Pipette cells several times by using a pipettor with a P1000 barrier tip. Perform a visual check to ensure that the cells are properly dissociated into either individual cells or small clumps. Avoid clumps that are larger than $200 \mu \mathrm{m}$ in size as they may not spread out well or could fail to exhibit differentiated podocyte morphology at the end of the induction timeline (Fig. 2, dotted circle).

vii. To stop the enzymatic activity of Trypsin, add about $2 \mathrm{~mL}$ of the Trypsin neutralizing solution to each well.

viii. Transfer the cell suspension into a $50 \mathrm{ml}$ conical tube and bring to $50 \mathrm{ml}$ volume with DMEM/F12.

ix. $\quad$ Centrifuge cells for $5 \mathrm{~min}$ at $201 \mathrm{xg}(1000 \mathrm{rpm})$.

x. Aspirate supernatant and resuspend the cells with the podocyte induction medium at a volume appropriate for a 1:4 splitting ratio. 
xi. Add cell suspension to the newly prepared laminin 511-E8-coated plate and shake plates gently to distribute the cells.

xii. Incubate the cells at $37^{\circ} \mathrm{C}$ and $5 \% \mathrm{CO}_{2}$. Refresh medium daily. The iPS cellderived podocytes can be used for further studies or maintained in culture by feeding them every two days with complete medium with CultureBoost-R (with or without serum, see Reagents). We recommend using the human iPS cellderived podocytes for additional experiments within 1-2 weeks after differentiation.

\section{TROUBLESHOOTING}

\section{End-point analysis of human iPS cell-derived podocytes differentiated in tissue culture plates, immunostaining. Timing $2 \mathrm{~d}$}

xiii. After 4 or 5 days of induction, fix cells by incubating them with $4 \%(\mathrm{v} / \mathrm{v})$ paraformaldehyde in PBS for $30 \mathrm{~min}$ at room temperature.

xiv. Rinse cells three times with PBS

- $\quad$ PAUSE POINT Fixed cells may be stored in PBS at $4^{\circ} \mathrm{C}$ for up to two weeks without adverse effects.

xv. Permeabilize the cells with permeabilization buffer (see Reagent Setup) for 5 $\mathrm{min}$ at room temperature.

xvi. Incubate the cells with a blocking solution consisting of $2 \%(\mathrm{wt} / \mathrm{v}) \mathrm{BSA}$ and $0.125 \%(\mathrm{v} / \mathrm{v})$ triton X-100 in PBS for $30 \mathrm{~min}$ at room temperature.

xvii. Incubate cells with primary antibodies in permeabilization buffer for overnight at $4{ }^{\circ} \mathrm{C}$.

xviii. Wash cells three times with permeabilization buffer and then incubate them with secondary antibodies (1:1000) for 1 hour in permeabilization buffer. If immunostaining for multiple markers (such as nephrin, WT1, and podocin) in a single well, incubate the cells with one secondary antibody at a time.

xix. Counterstain the cells with DAPI (1:1000) in distilled water for 5 min. Wash cells three times with PBS.

xx. Observe the cells by using an immunofluorescence microscope. Images can be analyzed using standard software such as Fiji or Image ${ }^{72,73}$. Cells may also be analyzed by flow cytometry ${ }^{5}$ which will also enable evaluation of the differentiation efficiency. (Fig 3) CRITICAL STEP For flow cytometry analysis, we recommend that the differentiated podocytes are characterized for dual expression of lineage identification markers such as nephrin and podocin. Because the expression of associated markers of podocytes such as WT1 is not restricted to kidney podocytes, we recommend that the expression of this marker be examined in combination with either nephrin or podocin as we previously described. 


\section{Option B Differentiation of human iPS cell-derived podocytes in microfluidic devices and the establishment of the Glomerulus Chip TIMING 12 d}

i. Dissociate the iPS cell-derived intermediate mesoderm cells from the laminin 511-E8-coated plates by first rinsing them three times with DMEM/F12 followed by incubation with $0.05 \%$ Trypsin-ETDA $(0.5 \mathrm{~mL}$ per well of a 12 -well plate $)$ for approximately $3 \mathrm{~min}$. The timing depends on cell density and the iPS cell line.

ii. Scrape the cells with a cell lifter/scraper. Using a P1000 pipette with barrier tip, pipet the cell suspension several times to dissociate the cells. Individualized cells or small clumps $(<200 \mu \mathrm{m})$ are acceptable for seeding into the microfluidic chip (see box 3 for guidance on fabrication and preparation of the microfluidic chip).

iii. Add about $2 \mathrm{~mL}$ of Trypsin neutralizing solution to each well and transfer cell suspension to a $15 \mathrm{ml}$ conical tube. Bring tube to $15 \mathrm{ml}$ volume by using DMEM/F12 and centrifuge at $201 \mathrm{xg}(1000 \mathrm{rpm})$ for $5 \mathrm{~min}$.

iv. Resuspend the cells in DMEM/F12 and centrifuge once again at $201 \mathrm{xg}$ (1000 rpm) for 5 min.

v. Aspirate the supernatant and add an appropriate volume of the intermediate mesoderm medium to achieve a cell suspension of $\sim 2 \times 10^{6}$ cells $/ \mathrm{mL}$.

vi. Add about $30 \mu \mathrm{L}$ of the cell suspension to fill the top (urinary) channel of the device and inspect to ensure that there are no air bubbles trapped in the fluidic channel. This step can be repeated until there are no air bubbles observed in the device.

\section{a. TROUBLESHOOTING}

vii. Place the microfluidic chips at $37^{\circ} \mathrm{C}$ in a $5 \% \mathrm{CO}_{2}$ incubator for $3-4$ hours. Perform visual inspection to ensure that a complete monolayer of iPS cellderived intermediate mesoderm cells is achieved.

\section{a. TROUBLESHOOTING}

viii. Aspirate medium along with non-adhered cells from the top channel of the device and add fresh intermediate mesoderm medium to the same microfluidic channel.

ix. Incubate the microfluidic devices overnight at $37^{\circ} \mathrm{C}$ and $5 \% \mathrm{CO}_{2}$.

\section{a. TROUBLESHOOTING}

x. Remove media from both channels of the device and add $10 \mu \mathrm{L}$ of complete medium with CultureBoost-R to the bottom channel of the device which is lined by endothelial cells

xi. To start differentiation of the human iPS cell-derived intermediate mesoderm cells into podocytes, fill the top channel of the device with $30 \mu \mathrm{L}$ of podocyte induction medium while minimizing exposure of the chips to light. Incubate the chips again in static (no fluidic flow) at $37^{\circ} \mathrm{C}$ and $5 \% \mathrm{CO}_{2}$ for 24 hours. 
xii. Connect the cell-lined microfluidic chips to pre-sterilized reservoirs with the respective medium for each channel and continuously perfuse at a volumetric flow rate of $60 \mu \mathrm{L} / \mathrm{h}$ using a peristaltic pump. Then apply cyclic stretching (-85 $\mathrm{kPa}$ and $1 \mathrm{~Hz}$ to achieve $\sim 10 \%$ strain) by connecting the vacuum lines to the dedicated ports of the microfluidic chips. Replenish the medium in the reservoirs every 2 days. Culture the devices under these conditions for a minimum of 4 days. See Fig. 5d-g for example images of the experimental setup for microfluidic Organ Chip cultures.

\section{a. TROUBLESHOOTING}

xiii. After a total of $\sim 5$ days of culture in the podocyte induction medium, culture the human iPS cell-derived podocytes (in the top channel of the microfluidic device) with the same complete medium with CultureBoost-R as the endothelial cells cultured in the bottom channel. We typically use the chips for secondary applications such as immunofluorescence and filtration studies after they have been cultured under continuous perfusion and mechanical stain for a total of 12 days or more.

\section{TROUBLESHOOTING}

xiv. To perform end- point analysis of the kidney Glomerulus Chip follow option A for analysis by immunostaining and follow option $B$ for analysis by molecular filtration

\section{A. End-point analysis of the kidney Glomerulus Chip, immunostaining. Timing $2 \mathrm{~d}$}

i. Disconnect the microfluidic devices from the reservoirs and peristaltic pump of the chip. The microfluidic devices can be placed in a petri dish for handling.

ii. Aspirate medium from the microfluidic channels and fix the cells by incubating with 4\% (v/v) paraformaldehyde in PBS for $1 \mathrm{~h}$ at room temperature.

iii. Rinse cells three times with PBS

PAUSE POINT Fixed microfluidic devices may be stored in PBS at $4{ }^{\circ} \mathrm{C}$ for up to two weeks without adverse effects.

iv. Permeabilize the cells with $0.125 \%(\mathrm{v} / \mathrm{v})$ Triton X-100 in PBS for $10 \mathrm{~min}$ at room temperature.

v. Incubate the cells with a blocking solution consisting of $2 \%(\mathrm{wt} / \mathrm{v}) \mathrm{BSA}$ and $0.125 \%(\mathrm{wt} / \mathrm{v})$ triton $\mathrm{X}-100$ in PBS for $2 \mathrm{~h}$ at room temperature.

vi. Incubate cells with primary antibodies in permeabilization buffer overnight at $4{ }^{\circ} \mathrm{C}$. For example, the top channel containing the human iPS cell-derived podocyte layer can be immunostained for nephrin or podocin, and the bottom channel containing the endothelial cells can be immunostained for VE-cadherin. CRITICAL STEP Since WT1 alone is not a definitive marker of kidney podocytes, we recommend immunostaining for multiple lineage identification 
markers such as nephrin and podocin at the end of the podocyte differentiation protocol.

vii. Wash cells three times (10 min each) with permeabilization buffer and then incubate them with secondary antibodies (1:1000) for 1 hour in permeabilization buffer at room temperature. If immunostaining for multiple markers (such as nephrin and podocin) in a single microfluidic device, incubate the cells with one secondary antibody at a time.

viii. Counterstain cells with DAPI (1:1000) in distilled water for $5 \mathrm{~min}$. Wash cells three times (5 min each) with PBS.

ix. Observe the cells by using a confocal microscope. Images can be analyzed using standard software such as Fiji or ImageJ ${ }^{72,73}$. 2D and 3D reconstructed images can also be generated by using IMARIS software ${ }^{5}$.

\section{B. End-point analysis of the kidney Glomerulus Chip, molecular filtration. Timing $1 \mathrm{~d}$}

i. Ensure that the microfluidic chips have been cultured for a minimum of 8 days under continuous perfusion and mechanical strain before proceeding to molecular filtration studies. Culture both the top and bottom channels of the celllined microfluidic device with complete medium containing CultureBoost-R without phenol red.

ii. Prepare a solution consisting of $10 \mu \mathrm{g} / \mathrm{mL}$ inulin-FITC and $100 \mu \mathrm{g} / \mathrm{mL}$ human albumin-TexasRed in complete medium with CultureBoost-R.

iii. Infuse the bottom (vascular) channel of the microfluidic device with the culture medium containing the fluorescently labeled inulin and albumin. The top (urinary) channel should be cultured with the regular complete medium with CultureBoost-R.

iv. Continuously perfuse the microfluidic chips for $6-8 \mathrm{~h}$ while applying cyclic strain. For each fluidic channel of the microfluidic device, collect media outflow in separate tubes.

v. Transfer $100 \mu \mathrm{L}$ of outflow from each channel into a clear bottom plate appropriate for fluorescence measurement and measure the fluorescence intensity of FITC and TexasRed using a plate reader. We typically take three measurements for each condition and a minimum of three independent replicates per experimental condition.

vi. Calculate the amount of inulin-FITC or albumin-TexasRed filtered from the bottom microvascular channel to the top urinary channel by using the equation for renal clearance ${ }^{5}$ :

Urinary clearance $=([\mathrm{U}] \times \mathrm{UV}) /[\mathrm{P}]$

Where $[U]=$ urinary concentration (podocyte channel), UV = urinary volume, and $[P]=$ plasma or microvascular concentration (endothelial channel). Percent urinary clearance can be calculated from a ratio of urinary clearance to urinary volume. 
vii. Data can be analyzed and visualized with GraphPad Prism or Microsoft Office Excel. We used GraphPad Prism v7 and Microsoft Excel 2016 for data analysis.

\section{TROUBLESHOOTING}

Troubleshooting advice can be found in Table 1.

\section{- Timing}

Steps 1-9, Maintenance of human iPS cells in feeder-free culture with mTeSR medium: $\sim 7 \mathrm{~d}$

Step 10, Preparation of human iPS cells for differentiation: $\sim 4 \mathrm{~d}$

Steps 11-20, Differentiation of human iPS cells intro mesoderm cells: $2 \mathrm{~d}$

Steps 21-25, Differentiation of human iPS cell-derived mesoderm into intermediate mesoderm cells: $\sim 14 \mathrm{~d}$

Option A, i-xii, Derivation of mature kidney podocytes using laminin-coated tissue culture plates: $4-5 \mathrm{~d}$

Option A, xiii-xx, End-point analysis of human iPS cell-derived podocytes differentiated in tissue culture plates, immunostaining. $\sim 2 \mathrm{~d}$

Start Box, Box 3, 1-8, Microfabrication of microfluidic organ-on-a-chip device: $\sim 4 \mathrm{~d}$

Start Box, Box 3, 9-17, Preparation of microfluidic devices for cell culture: $1 \mathrm{~d}$

Option B, i-xiii, Differentiation of human iPS cell-derived podocytes in microfluidic devices and the establishment of the Glomerulus Chip: $\sim 12 \mathrm{~d}$

Step xxviii, A and B, End-point analyses of kidney Glomerulus Chip: 2-5 d

Box 1, Protocol for passaging of human iPS cell-derived intermediate mesoderm cells: $3 \mathrm{hr}$

Box 2, Protocol for cryopreservation of human iPS cell-derived intermediate mesoderm cells: $\sim 30 \mathrm{~min}$

\section{ANTICIPATED RESULTS}

This protocol provides a detailed procedure for directed differentiation of human PSCs (including ES and iPS cell lines) into mature kidney glomerular podocytes, and their application in a microfluidic Organ Chip device to create a functional in vitro model of the human kidney glomerular capillary wall. With this protocol, human iPS cells can be differentiated first into mesoderm cells within 2 days, followed by the generation of intermediate mesoderm cells in about 16 days, and finally induced into mature glomerular podocytes by 21 days of directed differentiation (Fig. 1 and 2). The mesoderm cells express the lineage markers hand1, goosecoid, and brachyury (Fig. 3a). The intermediate mesoderm cells express WT1 and Pax2 (Fig. 3b), and although they transiently express OSR1 within the first 10 days of differentiation, they should not express the mesodermal marker, 
brachyury, after 16 days of differentiation ${ }^{5}$. Subsequent treatment of the intermediate mesoderm cells with the podocyte induction medium described in this report enables the derivation of kidney podocytes with morphological and molecular characteristics of the mature phenotype (Fig. 3c-e).

Whole transcriptome analysis (Supplementary Methods) revealed that the human iPS cellderived podocytes are more similar to an established human podocyte cell line than the undifferentiated iPS cells based on a global gene expression profile (Fig. 4a and Supplementary Fig. 2). Consistent with the functional characterization ${ }^{5}$, the human iPS cellderived podocytes express higher levels of genes that play critical roles in the lineage specification and functional maturation of kidney glomerular podocytes in vivo, which include SYNPO, MAF, PODXL, MAP1LC3B and EFNB2 (encode synapopodin, Maf, podocalyxin, microtubule associated protein 1, and ephrin B2, respectively) (Fig. 4b). Given the substantial contribution of podocytes to the GBM composition in vivo ${ }^{74-76}$, it is Intriguing that the human iPS cell-derived podocytes also exhibit significant upregulation of several genes including COL5A1, COL6A3, LAMA2, MXRA8, MRA5 and CHPF that are involved in the synthesis and remodeling of the GBM. This differentiation protocol might therefore provide an opportunity to model human kidney development and disease pathogenesis in vitro.

To develop an in vitro model of the glomerular capillary wall using microfluidic Organ Chip technology, we recommend that researchers differentiate the podocytes in situ, rather that terminally differentiating the cells on traditional tissue culture plates and then transferring them to the microfluidic cell culture system. In addition to enhancing differentiation phenotype (when fluid flow and mechanical strain are applied), this also prevents damage to the podocytes as typically results from treatment with cell dissociation enzymes such as trypsin. Differentiation of the human iPS cell-derived podocytes and co-culture with primary human glomerular endothelial cells on opposing sides of the flexible PDMS membrane in the microfluidic device (Fig. 5c) enables the establishment of a human kidney Glomerulus Chip (Fig. 6a and b) where the interfaced podocyte and endothelial cell layers express nephrin and VE-cadherin, respectively (Fig. 6c). Together, this protocol provides a chemically-defined method for the derivation of mature podocytes that recapitulate the structure and function of the kidney glomerular capillary wall in a microfluidic Organ Chip. Depending on the goal of the experiment, the cell-lined microfluidic device can be maintained in culture for at least a month. This microfluidic model can be used to study the selective molecular filtration function as well as drug toxicities of the human kidney glomerulus in vitro ${ }^{5}$. This protocol may also be useful for 3D bioprinting of organs, tissue engineering, and regenerative medicine in the future.

\section{Supplementary Material}

Refer to Web version on PubMed Central for supplementary material.

\section{Acknowledgements}

This work was supported by the Defense Advanced Research Projects Agency under Cooperative Agreement Number W911NF-12-2-0036 and the Wyss Institute for Biologically Inspired Engineering at Harvard University. 
S.M. was supported by a Dean's Postdoctoral Fellowship from Harvard Medical School, a UNCF-Merck Postdoctoral Fellowship, a Postdoctoral Enrichment Program Award from the Burroughs Wellcome Fund, and an NIH/NIDDK Nephrology Training Grant (4T32DK007199-39). We thank the Wyss Institute Microfabrication team for engineering the microfluidic devices, S. Jeanty for providing photographs of the setup for microfluidic Organ

Chip culture, P.K. Tetteh for helpful suggestions, and O. Levy and R. Prantil-Baun for comments on the manuscript.

\section{References}

1. Thomson J et al. Embryonic Stem Cell Lines Derived from Human Blastocysts. Science 282, 11451147 (1998). [PubMed: 9804556]

2. Takahashi K et al. Induction of Pluripotent Stem Cells from Adult Human Fibroblasts by Defined Factors. Cell 131, 861-872 (2007). [PubMed: 18035408]

3. Benam KH et al. Engineered in vitro disease models. Annu Rev Pathol 10, 195-262 (2015). [PubMed: 25621660]

4. Tabar V \& Studer L Pluripotent stem cells in regenerative medicine: challenges and recent progress. Nature reviews. Genetics 15, 82-92 (2014).

5. Musah S et al. Mature induced-pluripotent-stem-cell-derived human podocytes reconstitute kidney glomerular-capillary-wall function on a chip. Nat Biomed Eng 1, s41551-017-0069 (2017).

6. Ingber DE \& Musah S Methods for generation of podocytes from pluripotent stem cells and cells produced by the same. (2015).

7. Mooney DJ, Langer R \& Ingber DE Cytoskeletal filament assembly and the control of cell spreading and function by extracellular matrix. Journal of cell science 108 (Pt 6), 2311-20 (1995). [PubMed: 7673351]

8. Jones L \& Wagers A No place like home: anatomy and function of the stem cell niche. Nature Reviews Molecular Cell Biology 9, 11-21 (2008). [PubMed: 18097443]

9. Ingber D Mechanical control of tissue morphogenesis during embryological development. The International Journal of Developmental Biology 50, 255-266 (2006). [PubMed: 16479493]

10. Watanabe $\mathrm{K}$ et al. A ROCK inhibitor permits survival of dissociated human embryonic stem cells. Nature Biotechnology 25, 681-686 (2007).

11. Mummery $\mathrm{C}$ et al. Differentiation of human embryonic stem cells and induced pluripotent stem cells to cardiomyocytes: a methods overview. Circulation research 111, 344-58 (2012). [PubMed: 22821908]

12. Derda R et al. High-throughput discovery of synthetic surfaces that support proliferation of pluripotent cells. J. Am. Chem. Soc 132, 1289-95 (2010). [PubMed: 20067240]

13. Musah $\mathrm{S}$ et al. Glycosaminoglycan-binding hydrogels enable mechanical control of human pluripotent stem cell self-renewal. ACS Nano 6, 10168-77 (2012). [PubMed: 23005914]

14. Musah $S$ et al. Substratum-induced differentiation of human pluripotent stem cells reveals the coactivator YAP is a potent regulator of neuronal specification. Proc. Natl. Acad. Sci. U.S.A. 111, 13805-10 (2014). [PubMed: 25201954]

15. Li D et al. Role of mechanical factors in fate decisions of stem cells. Regenerative medicine 6, 229-240 (2011). [PubMed: 21391856]

16. Kanasaki $\mathrm{K}$ et al. Integrin beta1-mediated matrix assembly and signaling are critical for the normal development and function of the kidney glomerulus. Developmental biology 313, 584-93 (2008). [PubMed: 18082680]

17. Pozzi A et al. $\beta 1$ integrin expression by podocytes is required to maintain glomerular structural integrity. Developmental Biology 316, 288-301 (2008). [PubMed: 18328474]

18. Rodin S et al. Long-term self-renewal of human pluripotent stem cells on human recombinant laminin-511. Nature Biotechnology 28, 611-615 (2010).

19. Miyazaki T et al. Laminin E8 fragments support efficient adhesion and expansion of dissociated human pluripotent stem cells. Nature communications 3, 1236 (2012).

20. Mae S-I et al. Monitoring and robust induction of nephrogenic intermediate mesoderm from human pluripotent stem cells. Nature Communications 4, 1367- (2013).

21. Takasato $\mathrm{M}$ et al. Kidney organoids from human iPS cells contain multiple lineages and model human nephrogenesis. Nature 526, 564-568 (2015). [PubMed: 26444236] 
22. Morizane R et al. Nephron organoids derived from human pluripotent stem cells model kidney development and injury. Nat. Biotechnol 33, 1193-200 (2015). [PubMed: 26458176]

23. Kriz Hähnel, Rösener \& Elger. Long-term treatment of rats with FGF-2 results in focal segmental glomerulosclerosis. Kidney international 48, 1435-50 (1995). [PubMed: 8544400]

24 . Floege et al. Visceral glomerular epithelial cells can proliferate in vivo and synthesize plateletderived growth factor B-chain. The American journal of pathology 142, 637-50 (1993). [PubMed: 8434653]

25. Takeuchi et al. Basic fibroblast growth factor promotes proliferation of rat glomerular visceral epithelial cells in vitro. The American journal of pathology 141, 107-16 (1992). [PubMed: 1632456]

26. Shirato I Podocyte process effacement in vivo. Microscopy research and technique 57, 241-6 (2002). [PubMed: 12012392]

27. Huh D et al. Microfabrication of human organs-on-chips. Nat Protoc 8, 2135-2157 (2013). [PubMed: 24113786]

28. Huh D et al. Reconstituting Organ-Level Lung Functions on a Chip. Science 328, 1662-1668 (2010). [PubMed: 20576885]

29. Peti-Peterdi J, Kidokoro K \& Riquier-Brison A Novel in vivo techniques to visualize kidney anatomy and function. Kidney international 88, 44-51 (2015). [PubMed: 25738253]

30. Hendry C et al. Direct transcriptional reprogramming of adult cells to embryonic nephron progenitors. Journal of the American Society of Nephrology: JASN 24, 1424-34 (2013). [PubMed: 23766537]

31. Lam AQ et al. Rapid and efficient differentiation of human pluripotent stem cells into intermediate mesoderm that forms tubules expressing kidney proximal tubular markers. J. Am. Soc. Nephrol 25, 1211-25 (2014). [PubMed: 24357672]

32. Morizane R \& Bonventre JV Generation of nephron progenitor cells and kidney organoids from human pluripotent stem cells. Nat Protoc 12, 195-207 (2017). [PubMed: 28005067]

33. Takasato et al. Directing human embryonic stem cell differentiation towards a renal lineage generates a self-organizing kidney. Nature Cell Biology 16, 118-126 (2014). [PubMed: 24335651]

34. Reiser J \& Sever S Podocyte Biology and Pathogenesis of Kidney Disease. Annual Review of Medicine 64, 357-366 (2013).

35. Büscher A \& Weber S Educational paper. Eur J Pediatr 171, 1151-1160 (2012). [PubMed: 22237399]

36. Friedman D \& Pollak M Genetics of kidney failure and the evolving story of APOL1. Journal of Clinical Investigation 121, 3367-3374 (2011). [PubMed: 21881214]

37. Devuyst O, Knoers NV, Remuzzi G \& Schaefer F Rare inherited kidney diseases: challenges, opportunities, and perspectives. Lancet 383, 1844-59 (2014). [PubMed: 24856029]

38. Edwards JK Glomerular disease: Novel candidate genes implicated in FSGS. Nat Rev Nephrol 12, 256 (2016).

39. Greek R \& Menache A Systematic reviews of animal models: methodology versus epistemology. International journal of medical sciences 10, 206-21 (2013). [PubMed: 23372426]

40. Yang L, Yang J, Byrne S, Pan J \& Church G CRISPR/Cas9-Directed Genome Editing of Cultured Cells. Current Protocols in Molecular Biology 31.1.1-31.1.17 (2014). doi: 10.1002/0471142727.mb3101s107

41. Jang K-J et al. Human kidney proximal tubule-on-a-chip for drug transport and nephrotoxicity assessment. Integrative Biology 5, 1119-1129 (2013). [PubMed: 23644926]

42. Nieskens T \& Wilmer M Kidney-on-a-chip technology for renal proximal tubule tissue reconstruction. European journal of pharmacology, 46-56 (2016). doi:10.1016/j.ejphar. 2016.07.018

43. Benam KH et al. Small airway-on-a-chip enables analysis of human lung inflammation and drug responses in vitro. Nat. Methods 13, 151-7 (2016). [PubMed: 26689262]

44. Maschmeyer I et al. A four-organ-chip for interconnected long-term co-culture of human intestine, liver, skin and kidney equivalents. Lab on a chip 15, 2688-2699 (2015). doi:10.1039/c5lc00392j [PubMed: 25996126] 
45. Chang S-Y, Weber E, Ness K, Eaton D \& Kelly E Liver and Kidney on Chips: Microphysiological Models to Understand Transporter Function. Clinical pharmacology and therapeutics 464-478 (2016). doi:10.1002/cpt.436 [PubMed: 27448090]

46. Materne E-M et al. The Multi-organ Chip - A Microfluidic Platform for Long-term Multi-tissue Coculture. Journal of visualized experiments : JoVE 98, e52526 (2015). doi:10.3791/52526

47. Kim H, Li H, Collins J \& Ingber D Contributions of microbiome and mechanical deformation to intestinal bacterial overgrowth and inflammation in a human gut-on-a-chip. Proceedings of the National Academy of Sciences of the United States of America 113, E7-15 (2016). [PubMed: 26668389]

48. Torisawa $Y$ et al. Bone marrow-on-a-chip replicates hematopoietic niche physiology in vitro. Nature methods 11, 663-9 (2014). [PubMed: 24793454]

49. Ingber D Reverse Engineering Human Pathophysiology with Organs-on-Chips. Cell 164, 1105-9 (2016). [PubMed: 26967278]

50. Bhatia S \& Ingber D Microfluidic organs-on-chips. Nature biotechnology 32, 760-72 (2014).

51. Prantil-Baun R, Novak R \& of ... D. -D Physiologically-Based Pharmacokinetic and Pharmacodynamic Analysis Enabled by Microfluidically Linked Organs-on-Chips. Annual Review of Pharmacology and Toxicology 58, 37-64 (2018). doi:10.1146/annurevpharmtox-010716-104748

52. Unknown. Tissue Engineering and Regenerative Medicine. J Tissue Eng Regen M 6, 1-429 (2012).

53. Miller J et al. Rapid casting of patterned vascular networks for perfusable engineered threedimensional tissues. Nature Materials 11, 768-774 (2012). [PubMed: 22751181]

54. Kolesky D et al. 3D Bioprinting of Vascularized, Heterogeneous Cell-Laden Tissue Constructs. Advanced Materials 26, 3124-3130 (2014). [PubMed: 24550124]

55. Chung H, Ko I, Atala A \& Yoo J Cell-based therapy for kidney disease. Korean J Urology 56, 412421 (2015).

56. LAN, SALEEM M \& MATHIESON P Podocyte culture: Tricks of the trade. Nephrology 17, 525531 (2012). [PubMed: 22591222]

57. Saleem MA One hundred ways to kill a podocyte. Nephrology Dialysis Transplantation 30, 12661271 (2015).

58. Shankland, Pippin, Reiser \& Mundel. Podocytes in culture: past, present, and future. Kidney Int 72 , 26-36 (2007). [PubMed: 17457377]

59. Song B et al. The Directed Differentiation of Human iPS Cells into Kidney Podocytes. Plos One 7, e46453 (2012). [PubMed: 23029522]

60. Ciampi $\mathrm{O}$ et al. Generation of functional podocytes from human induced pluripotent stem cells. Stem Cell Research 17, 130-139 (2016). [PubMed: 27299470]

61. Bock C et al. Reference Maps of Human ES and iPS Cell Variation Enable High-Throughput Characterization of Pluripotent Cell Lines. Cell 144, 439-452 (2011). [PubMed: 21295703]

62. Sances $S$ et al. Modeling ALS with motor neurons derived from human induced pluripotent stem cells. Nature neuroscience 19, 542-53 (2016). [PubMed: 27021939]

63. Johnson A, Weick J, Pearce R \& Zhang S-C Functional Neural Development from Human Embryonic Stem Cells: Accelerated Synaptic Activity via Astrocyte Coculture. The Journal of Neuroscience 27, 3069-3077 (2007). [PubMed: 17376968]

64. Busskamp V et al. Rapid neurogenesis through transcriptional activation in human stem cells. Molecular systems biology 10, 760 (2014). [PubMed: 25403753]

65. Chavez A et al. Highly efficient Cas9-mediated transcriptional programming. Nature Methods 12 , 326-328 (2015). doi:10.1038/nmeth.3312 [PubMed: 25730490]

66. Murphy W, McDevitt T \& Engler A Materials as stem cell regulators. Nature Materials 13, 547557 (2014). [PubMed: 24845994]

67. Mammoto T \& Ingber D Mechanical control of tissue and organ development. Development 137, 1407-1420 (2010). [PubMed: 20388652]

68. Borysiak $\mathrm{M}$ et al. Simple replica micromolding of biocompatible styrenic elastomers. Lab on a chip 13, 2773-84 (2013). [PubMed: 23670166] 
69. Domansky K et al. Clear castable polyurethane elastomer for fabrication of microfluidic devices. Lab on a chip 13, 3956-64 (2013). [PubMed: 23954953]

70. Rayat, Joshi, Sakhuja \& Datta. Glomerular basement membrane thickness in normal adults and its application to the diagnosis of thin basement membrane disease: an Indian study. Indian journal of pathology \& microbiology 48, 453-458 (2005). [PubMed: 16366093]

71. Puleo C, Ambrose W, Takezawa T, Elisseeff J \& Wang T-H Integration and application of vitrified collagen in multilayered microfluidic devices for corneal microtissue culture. Lab on a chip 9, 3221-7 (2009). [PubMed: 19865728]

72. Schindelin J et al. Fiji: an open-source platform for biological-image analysis. Nature Methods 9 , 676-682 (2012). [PubMed: 22743772]

73. Schneider C, Rasband W \& Eliceiri K NIH Image to ImageJ: 25 years of image analysis. Nature methods 9, 671-675 (2012). [PubMed: 22930834]

74. Abrahamson D Role of the Podocyte (and Glomerular Endothelium) in Building the GBM. Seminars in Nephrology 32, 342-349 (2012). [PubMed: 22958488]

75. Abrahamson D, Hudson B, Stroganova L, Borza D-B \& John P Cellular origins of type IV collagen networks in developing glomeruli. Journal of the American Society of Nephrology : JASN 20, 1471-9 (2009). [PubMed: 19423686]

76. Miner J Organogenesis of the kidney glomerulus: focus on the glomerular basement membrane. Organogenesis 7, 75-82 (2011). [PubMed: 21519194] 


\section{Box 1|}

\section{Protocol for passaging of human iPS cell-derived intermediate mesoderm cells. Timing $\sim 3 \mathrm{hr}$}

We recommend that the cells are cultured in the intermediate mesoderm (Fig. 1) induction medium for a minimum of 7 days before passaging onto newly prepared laminin 511-E8-coated plates. It is acceptable for these cells to reach $100 \%$ confluence before passaging.

\section{Procedure}

1. Prepare laminin 511-E8-coated plates (see Reagent Setup).

2. Prepare intermediate mesoderm differentiation medium (see Reagent Setup).

3. Rinse the cells 3 times with pre-warmed DMEM/F12 and add $0.5 \mathrm{~mL}$ of $0.05 \%$ Trypsin-EDTA per 12-well plate.

4. Incubate the cells at $37^{\circ} \mathrm{C}$ and $5 \% \mathrm{CO}_{2}$ for $\sim 3$ min or until the cells begin to dissociate or ball up. Colonies with defined borders may begin the roll up at the edge. Timing depends on cell density.

5. Add about $2 \mathrm{~mL}$ of Trypsin neutralizing solution to each well and gently scrape the cells using a cell lifter.

6. Pipette cell suspension several times to form a mixture of single cells and small clumps $(<200 \mu \mathrm{m})$.

7. Transfer cell suspension to a conical tube and bring to volume with prewarmed DMEM/F.

8. Centrifuge for $5 \mathrm{~min}$ at $201 \mathrm{xg}(1000 \mathrm{rpm})$ at room temperature.

9. Remove supernatant by aspiration. Be careful not to aspirate cell pellet.

10. Resuspend cells in an appropriate volume of the intermediate mesoderm differentiation medium for seeding at 1:4 or 1:6 splitting ratio.

11. Add $1 \mathrm{~mL}$ of cell suspension to each well of the newly prepared laminin 511E8-coated 12-well plates.

12. Incubate cells at $37^{\circ} \mathrm{C}$ and $5 \% \mathrm{CO}_{2}$ and refresh medium daily. 
Box 2|

\section{Protocol for cryopreservation of human iPS-derived intermediate mesoderm cells. Timing $\sim 30 \mathrm{~min}$}

We recommend a minimum of 16 days of differentiation (and one passaging if necessary) in the intermediate mesoderm stage (Fig. 1) before cryopreservation. It is also advisable to cryopreserve the cells while they are growing in the mitotic phase (within $\sim 5$ days after passaging). Growth rate depends on seeding density and the hPSC line used.

\section{Procedure}

1. Prepare intermediate mesoderm differentiation medium (see Reagent Setup).

2. Rinse the cells 3 times with pre-warmed DMEM/F12 and add $0.5 \mathrm{~mL}$ of $0.05 \%$ Trypsin-EDTA per 12 -well plate.

3. Incubate the cells at $37^{\circ} \mathrm{C}$ and $5 \% \mathrm{CO}_{2}$ for $\sim 3$ min or until the cells begin to dissociate or ball up. Colonies with defined boarders may begin the roll up at the edge. Timing depends on cell density.

4. Add about $2 \mathrm{~mL}$ of Trypsin neutralizing solution to each well and gently scrape the cells using a cell lifter.

5. Pipette cell suspension several times to form a mixture of single cells and small clumps $(<200 \mu \mathrm{m})$.

6. Transfer cell suspension to a conical tube and bring to volume with prewarmed DMEM/F. Take a small volume to count the cells.

7. Centrifuge the cells for $5 \mathrm{~min}$ at $201 \mathrm{xg}(1000 \mathrm{rpm})$ at room temperature.

8. Remove supernatant by aspiration. Be careful not to aspirate cell pellet.

9. Resuspend cells in an appropriate volume of a cryopreservation medium consisting of 50\% FBS, 40\% intermediate mesoderm differentiation medium, and $10 \%$ DMSO to obtain $\sim 1 \times 10^{6}$ cells per $\mathrm{mL}$.

10. Add $1 \mathrm{~mL}$ of cell suspension to each cryopreservation tube.

11. Plate tubes in a Mr. Frosty freezing container and freeze at $-80^{\circ} \mathrm{C}$ for $24 \mathrm{~h}$.

12. Move tubes to a liquid nitrogen cell storage tank for long-term cryopreservation.

To initiate live cultures, slowly thaw the cells using a water bath. Then resuspend cells in intermediate mesoderm differentiation medium and centrifuge for $5 \mathrm{~min}$ at $201 \mathrm{xg}$ (1000 $\mathrm{rpm})$ at room temperature. Remove supernatant and resuspend the cells in intermediate mesoderm differentiation medium. Plate cells on newly prepared laminin 511-coated plates and refresh medium daily. Cells can also be directly seeded in the microfluidic cell culture devices described in this protocol (Option B Differentiation of human iPS cellderived podocytes in microfluidic devices and the establishment of the Glomerulus Chip) 


\section{Microfabrication of microfluidic organ-on-a-chip device. TIMING $\sim 4 \mathrm{~d}$}

CRITICAL We previously published a detailed method for making Organ Chip microfluidic devices ${ }^{27}$. For this section of the protocol, we recommend that researchers refer to the published protocol for additional details and step-by-step instructions for engineering the microfluidic organ-on-a-chip device and following the considerations outlined below.

1. Develop mold out of Prototherm 12120 using stereolithography (Proto Labs).

2. Cast the 'urinary' and 'microvascular' channels of the devices from PDMS at a 10:1 w/w ratio of base to curing agent. Degas prepolymer mixture and then cure for $4 \mathrm{~h}$ to overnight at $60{ }^{\circ} \mathrm{C}$.

3. Cast the Glomerulus Chip so that it contains two fluidic channels $($ a $1 \times 1 \mathrm{~mm}$ urinary channel and $1 \times 0.2 \mathrm{~mm}$ microvascular channel), two vacuum channels parallel to the fluidic channels and ports for all fluidic and vacuum channels. Ensure that the urinary and microvascular channels of the device are separated by a porous PDMS membrane, which can be developed by casting against a DRIE-patterned silicon wafer $(50 \times 50 \mathrm{~mm})$ consisting of $50 \mu \mathrm{m}$ high and $7 \mu \mathrm{m}$ diameter posts spaced $40 \mu \mathrm{m}$ apart.

4. To produce through-holes in the membrane using the microengineered post array, pour $100 \mu \mathrm{L}$ of PDMS onto the wafer and then compress a polycarbonate backing against the post array, followed by baking at $60{ }^{\circ} \mathrm{C}$ for $4 \mathrm{~h}$.

5. Bond the porous PDMS membrane to the top component of the device by using oxygen plasma treatment ( $40 \mathrm{~W}, 800 \mathrm{mbar}, 40 \mathrm{~s}$ ).

6. Bond the top-membrane assembly to the bottom component containing the microvascular channel $(1 \mathrm{~mm}$ wide $\times 0.2 \mathrm{~mm}$ high) and matching vacuum channels.

7. For handling, place each microfluidic chip on a $25(\mathrm{~W}) \times 75(\mathrm{H}) \times 1(\mathrm{D}) \mathrm{mm}$ microscope glass slide.

8. PAUSE POINT Microfluidic chips can be used immediately or stored at room temperature for up to six months.

\section{Preparation of microfluidic devices for cell culture. TIMING $1 \mathrm{~d}$}

CRITICAL Microfluidic devices should be activated with oxygen plasma immediately before use.

9. Place microfluidic Organ Chip devices in a $150 \mathrm{~mm}$ cell culture dish which fits about eight chips. Avoid stacking the chips. Activate/sterilize the chips by treatment with oxygen plasma ( $100 \mathrm{~W}, 15$ s.c.c.m, 30 s). Quickly move the chips to sterile biosafety cabinet for ECM coating. Activated chips should be used within $15 \mathrm{~min}$. 
10. Functionalize the activated chips with full length laminin 511 protein (see Reagent Setup).

\section{TROUBLESHOOTING}

11. Prepare primary human glomerular endothelial cells as described in the reagent set-up. Dissociate the cells from a T25 flask, incubate them with 2 $\mathrm{mL}$ of $0.05 \%$ Trypsin-EDTA for $1 \mathrm{~min}$ at $37^{\circ} \mathrm{C}$ and stop the reaction by adding approximately $5 \mathrm{~mL}$ of Trypsin neutralizing solution (see Reagent Setup).

12. Transfer cell suspension into a $15-\mathrm{mL}$ conical tube and bring to $15 \mathrm{ml}$ volume with complete medium containing serum and CultureBoost-R. Centrifuge the cells for $5 \mathrm{~min}$ at $201 \mathrm{xg}(1000 \mathrm{rpm})$ at room temperature and aspirate the supernatant.

13. Resuspend the endothelial cells in an appropriate volume of complete medium with serum and CultureBoost-R to achieve a concentration of approximately $2 \times 10^{6}$ cells $/ \mathrm{mL}$.

14. Using a $100 \mu \mathrm{L}$ pipette with barrier tip, gently add $10 \mu \mathrm{L}$ of the cell suspension (about $2 \times 10^{4}$ cells) to the bottom (vascular) channel of the microfluidic device. We found that cell seeding density of $2 \times 10^{4}$ to $4 \times 10^{4}$ cells per channel work well.

\section{a. TROUBLESHOOTING}

15. Prior to incubation, fill the top (urinary) channel of the device with DMEM/F12 to minimize evaporation in the chip and prevent the laminincoated surface in the top channel from drying out. Incubate chips in an inverted position at $37^{\circ} \mathrm{C}$ and $5 \% \mathrm{CO}_{2}$ for 3 hours. CRITICAL STEP It is important that the chip is incubated in an inverted position to ensure that endothelial cells adhere to the flexible PDMS membrane separating the two channels, as this also positions the cells in a way that allows for the establishment of the endothelial—basement membrane—podocyte interface in vitro.

16. Perform visual inspection and ensure that a complete monolayer of endothelial cells is achieved before proceeding to the next step. The chip can now be used in the original orientation such that the endothelium-lined channel is on the bottom.

\section{a. TROUBLESHOOTING}

17. Remove non-adherent endothelial cells by gently pipetting the medium from the bottom channel of the microfluidic device. Then add $10 \mu \mathrm{L}$ of fresh medium to the endothelium-lined channel. 


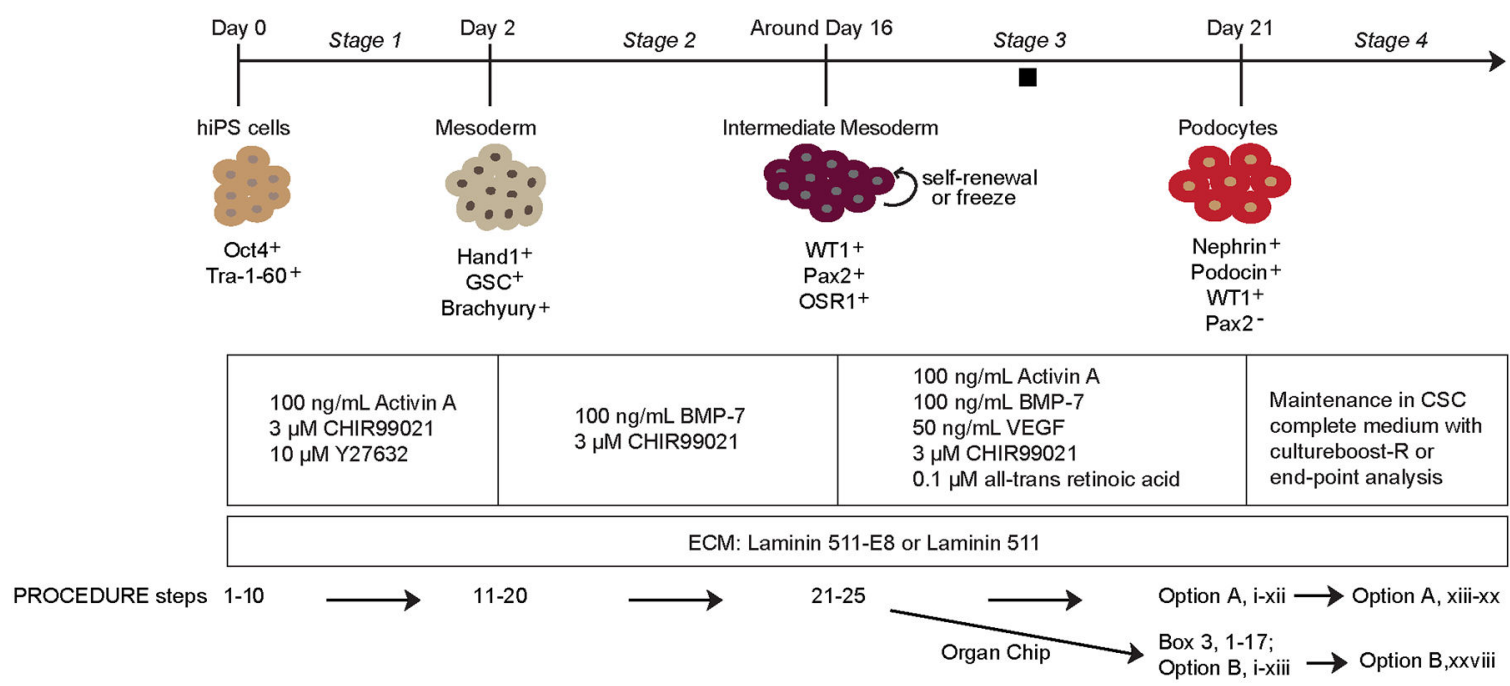

Figure 1|.

Schematic overview of the protocol for derivation of mature kidney glomerular podocytes from human iPS cells. The diagram shows sequential differentiation stages in the protocol. The concentrations of growth factors and signaling molecules are shown. Also shown are the markers used to characterize the cells at each stage of the differentiation protocol. Black square indicates a pause point, where the protocol may be paused and the intermediate mesoderm cells could be stored by cryopreservation. GSC, goosecoid; WT1, Wilm's tumor 1; OSR1, odd-skipped related transcription factor 1; BMP-7, bone morphogenetic protein 7; VEGF, vascular endothelial growth factor; ECM, extracellular matrix. Figure modified with permission from Reference 5 . 

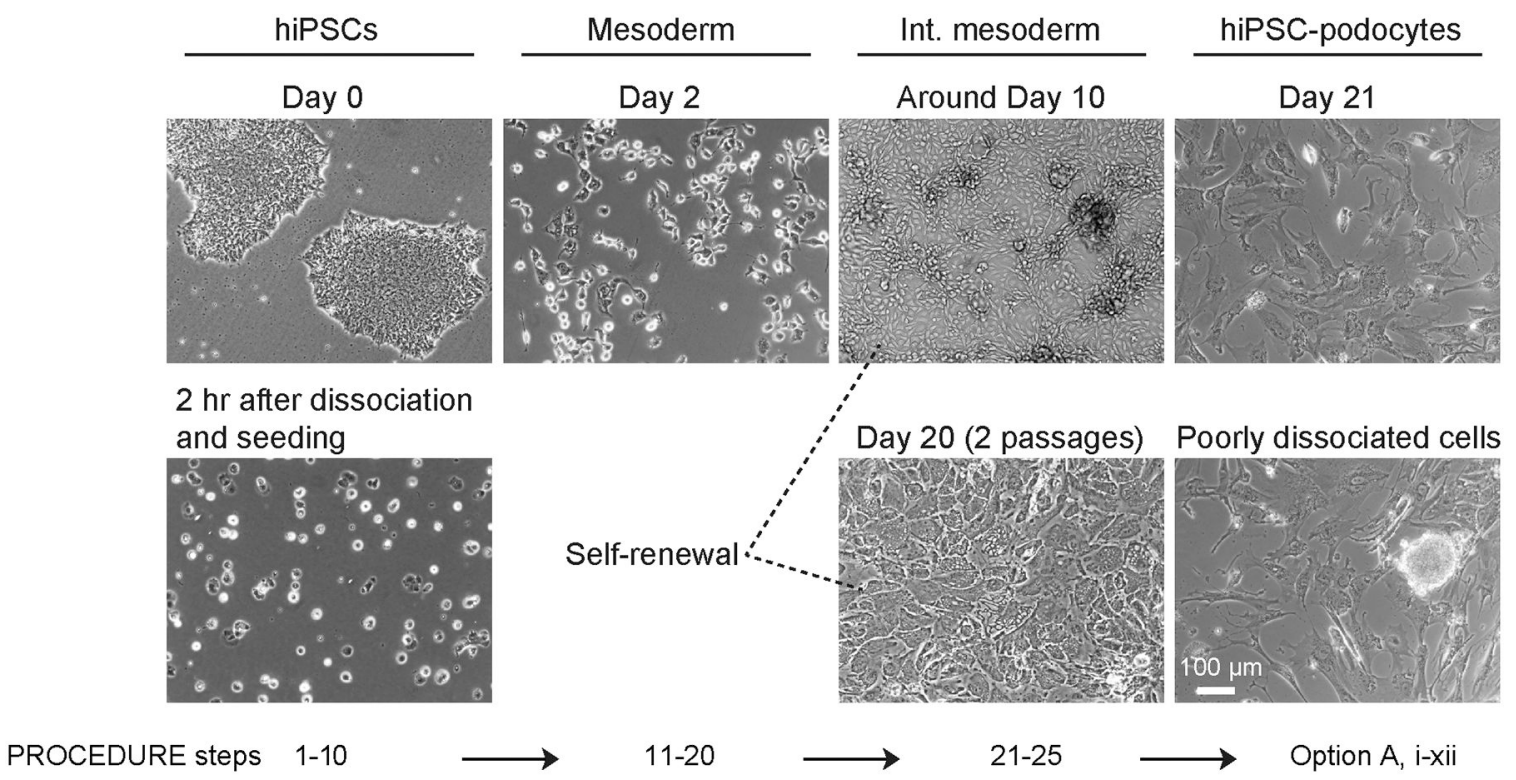

Figure 2|.

Morphological changes of human iPS cells at each stage of differentiation. Representative bright field images show human iPS cells before and after dissociation on day 0 when differentiation is initiated, mesoderm cells after 2 days of differentiation, intermediate mesoderm cells at around 10 days and after20 days of culture with two passages, as well as the terminally differentiated podocytes. An example of an image of podocytes derived from a population of cells containing a poorly dissociated colony (dotted red circle) is also shown. Int. mesoderm, intermediate mesoderm; hiPS-podocyte, human iPS cell-derived podocytes. Scale bar, $100 \mu \mathrm{m}$. 
a

Hand 1

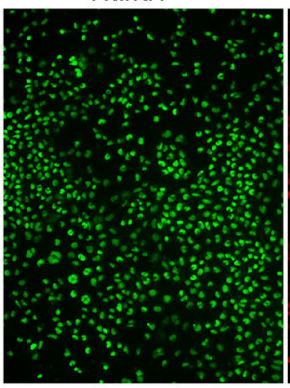

C

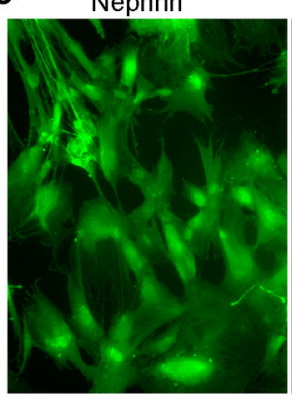

Goosecoid

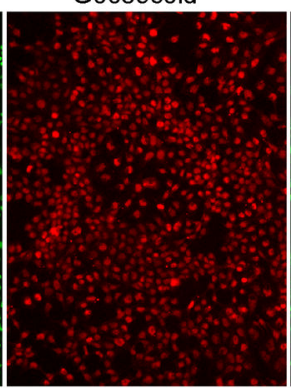

WT1

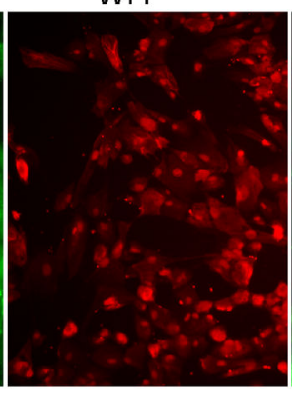

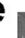

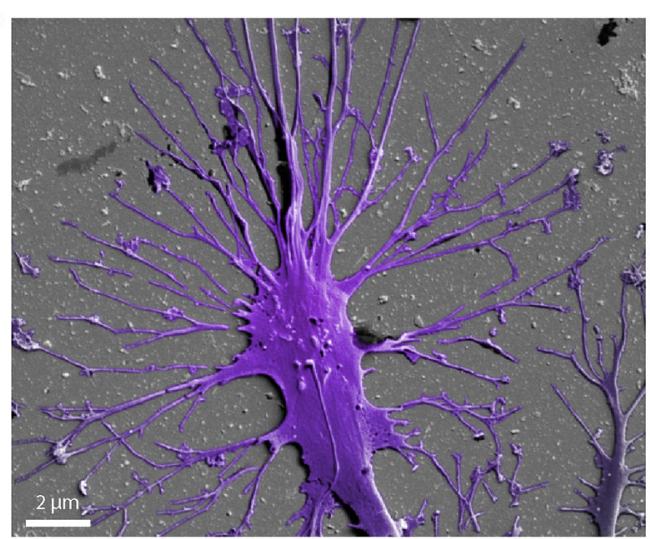

Podocin

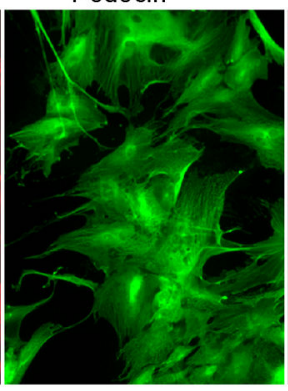

b
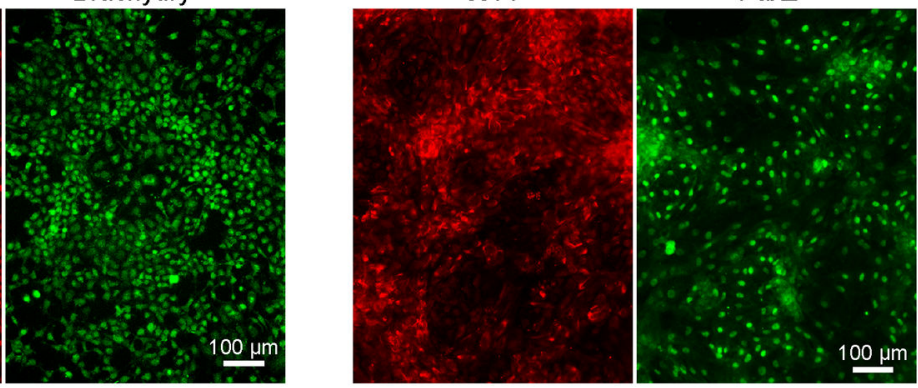

ApoL1

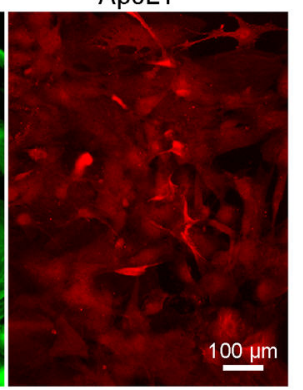

d Podocin ${ }^{+}$processes

Figure 3|.

Immunofluorescence staining and scanning electron micrograph of cells during the differentiation process. Human iPS cell-derived mesoderm cells expressing hand1, goosecoid, and brachyury (a), intermediate mesoderm cells expressing WT1 and Pax2 markers (b), and podocytes expressing lineage characterization markers nephrin, WT1 and podocin, as well as the associated protein ApoL1 (c). (d) High magnification image of iPS cell-derived podocytes showing the development of foot processes that are positive for podocin. (e) Scanning electron micrograph of human iPS-derived podocytes showing the development of primary and secondary foot processes. Figures d, e modified with permission from Reference 5. Scale bars, (a-c) $100 \mu \mathrm{m}$, (d) $25 \mu \mathrm{m}$, (e) $2 \mu \mathrm{m}$. 
a

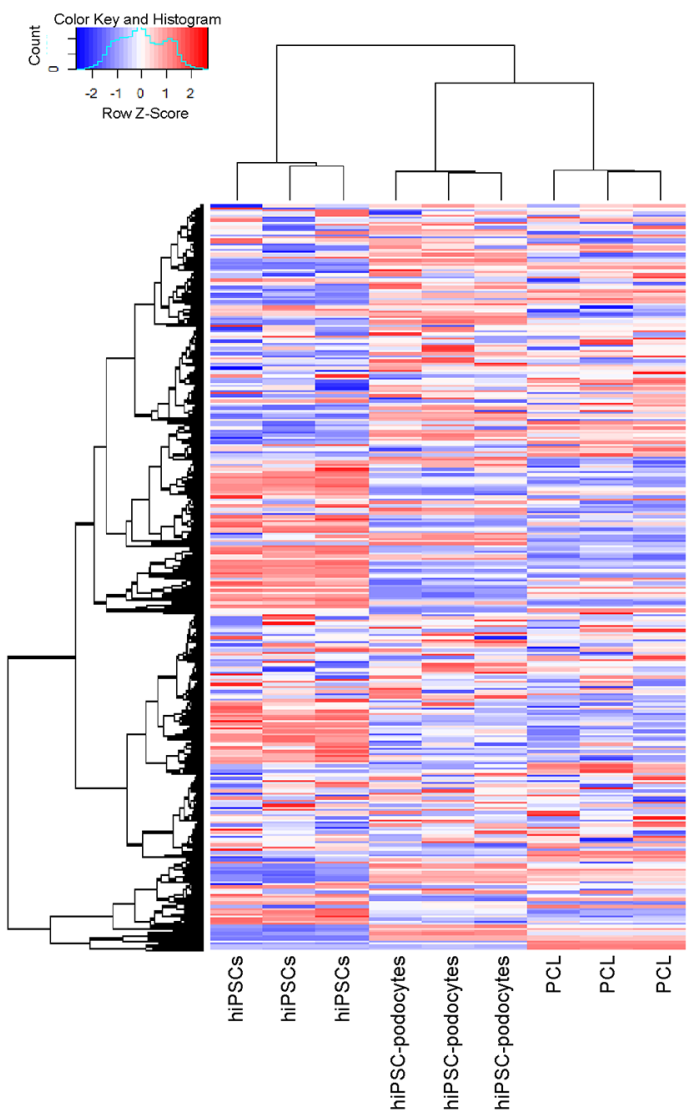

b

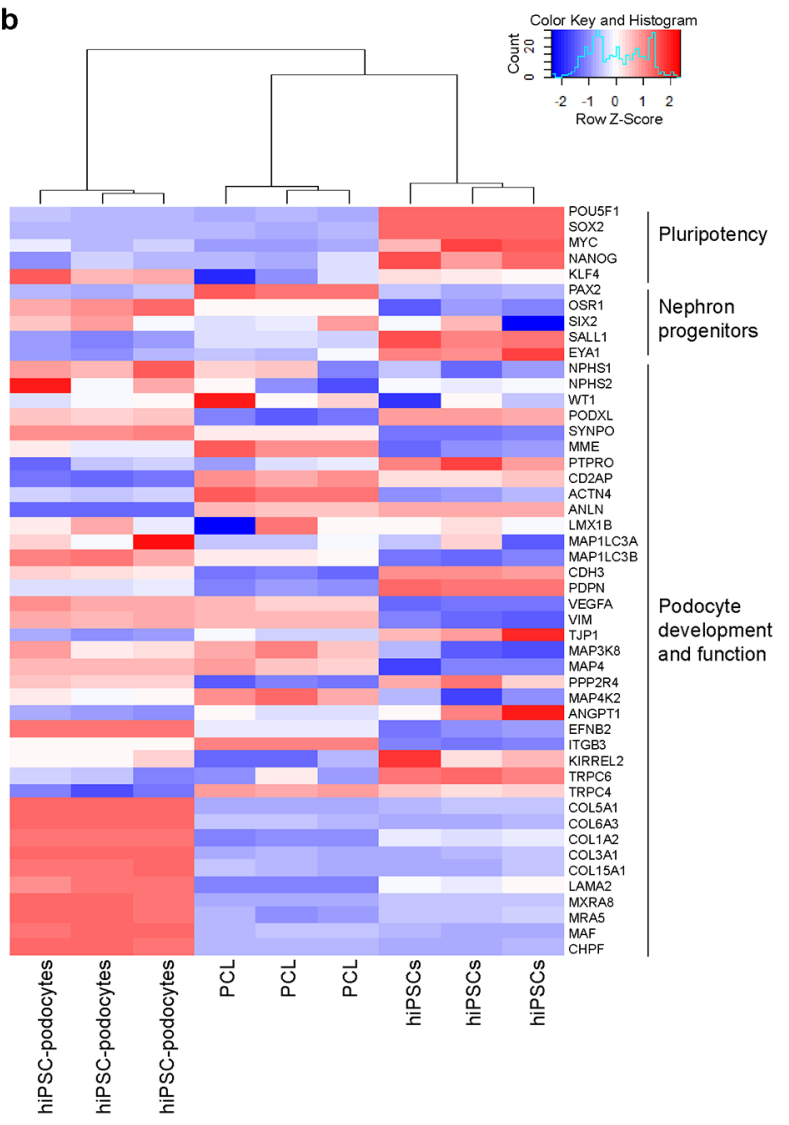

Figure 4|.

Whole transcriptome analysis using Affymetrix Human Gene 2.0 ST gene array. (a) Global gene expression profile of triplicate samples of undifferentiated human iPS cells, iPSderived podocytes, and an immortalized human glomerular podocyte cell line (PCL). (b) Expression levels of genes involved in pluripotency, development of nephrogenic progenitors, or lineage specification and functional maturation of kidney glomerular podocytes. Each replicate represents an independent experiment. See also Supplementary Data 1 and 2. Heatmaps depict genes that are up-regulated (red), down-regulated (blue), and unchanged (white). 
a
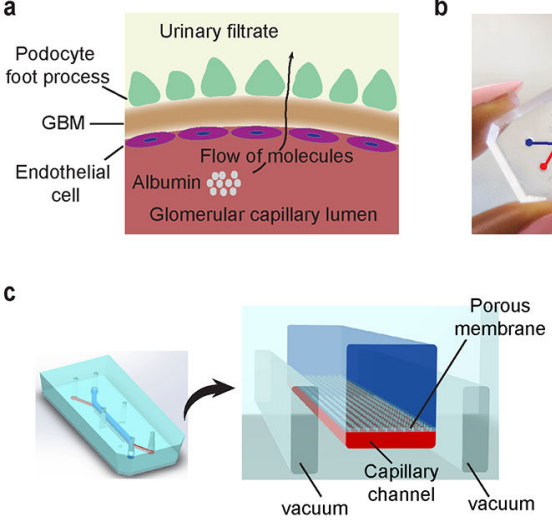

d

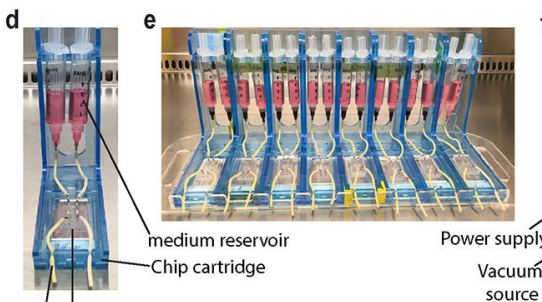

b
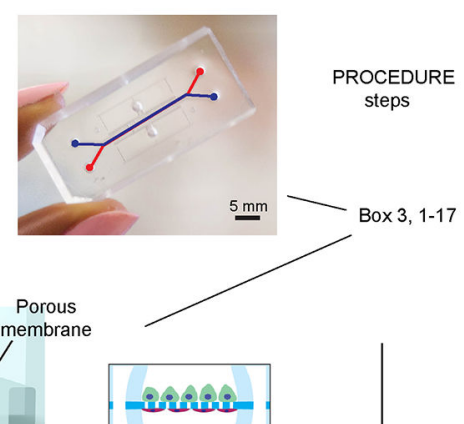

stretched

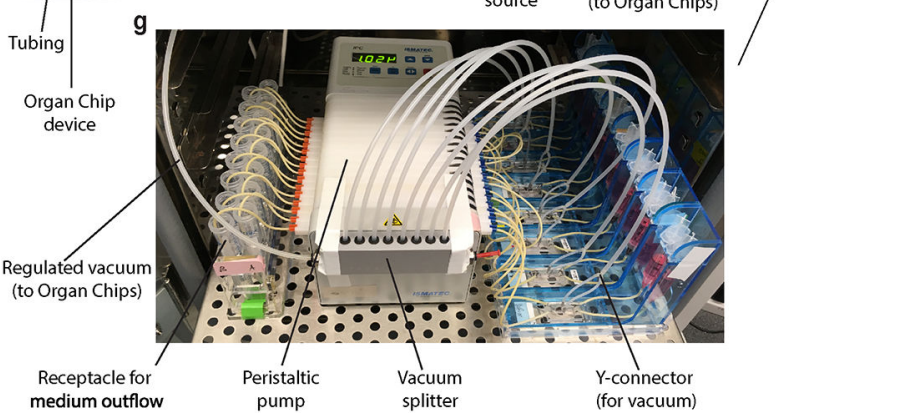

Figure 5|.

Design of microfluidic Organ Chip device to recapitulate the structure and function of the kidney glomerular capillary wall. (a) Schematic representation of the glomerular capillary wall showing podocyte and endothelial cell layers separated by the GBM to form capillary and urinary compartments. (b) Photograph of the microfluidic device engineered from PDMS. Scale bar, $5 \mathrm{~mm}$. (c) Schematic representation of the microfluidic kidney Glomerulus Chip with microchannels replicating the urinary and capillary compartments of the glomerulus. The GBM is mimicked by using a porous and flexible PDMS membrane functionalized with the protein laminin. Cyclic mechanical strain was applied to cell layers by stretching the flexible PDMS membrane using vacuum. Example photographs of the experimental setup for Glomerulus Chip cultures show (d) a single Organ Chip microfluidic device connected to two reservoirs containing cell culture media for the urinary (right) and capillary (left) channels, (e) multiple Organ Chips placed on a cartridge built-in-house for handling of microfluidic devices, (f) photograph of the programmable vacuum regulator system built-in-house, (g) complete setup of the microfluidic cell culture system with the Glomerulus Chips connected to media reservoirs, inlet and outlet tubing, vacuum lines for stretching, and the peristaltic pump, as well as receptacles for media outflow. Figure modified with permission from Reference 5. 
a

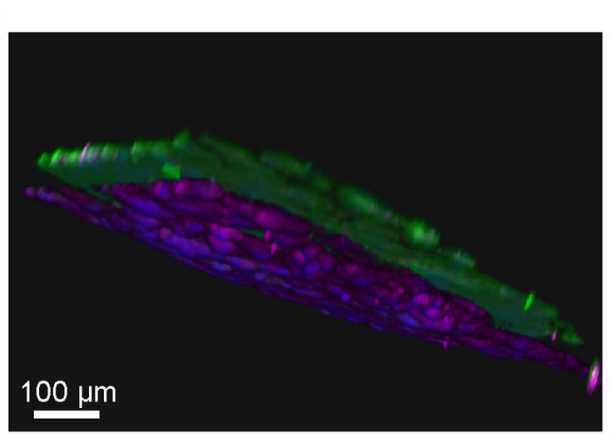

C

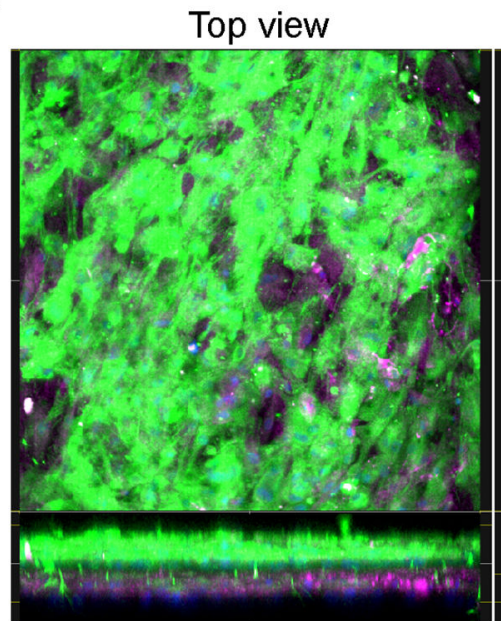

b

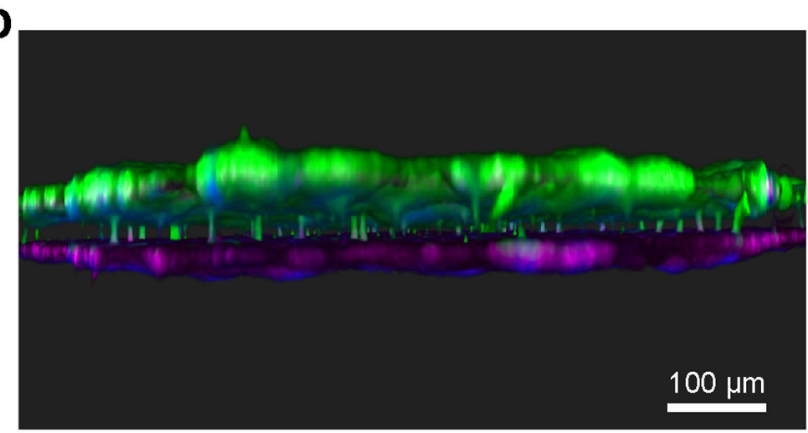

Endothelial layer

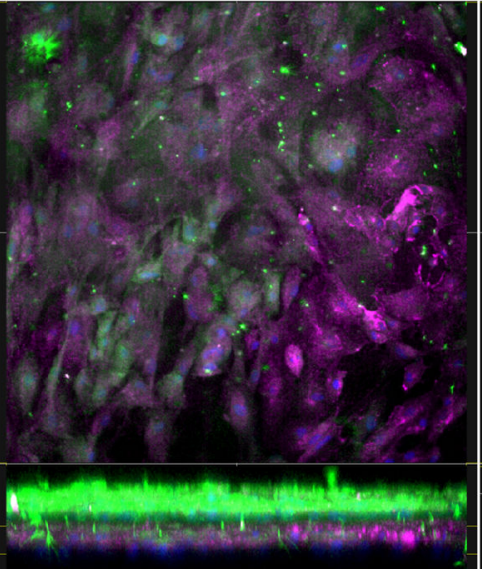

Podocyte layer

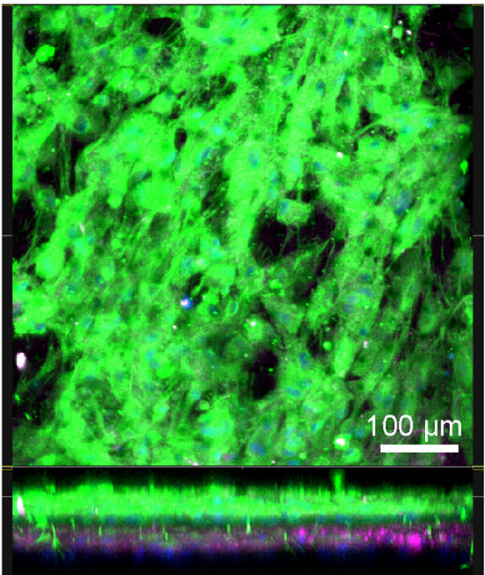

Figure 6|.

Fluorescence microscopy images of the human kidney Glomerulus Chip established from iPS cell-derived podocytes and primary glomerular endothelial cells. (a) Side and (b) crosssectional view of 3D reconstructed confocal images of the human Glomerulus Chip showing the iPS cell-derived podocytes and endothelial cells in their respective layers after differentiation and co-culture on opposing sides of the flexible ECM-coated PDMS membrane. (c) Additional immunofluorescence confocal images showing a top view of both cell layers (left), the endothelial cell layer only (middle), and the human iPS cell-derived podocyte layer (right). Scale bars, $100 \mu \mathrm{m}$. Figure modified with permission from Reference 5. 
TABLE 1|

Troubleshooting table.

\begin{tabular}{|c|c|c|}
\hline Step & Problem & Solution \\
\hline 5 & $\begin{array}{l}\text { The human iPS cells completely } \\
\text { dissociated from Matrigel- } \\
\text { coated plate after treatment with } \\
\text { Accutase }\end{array}$ & $\begin{array}{l}\text { If most of the human iPS cells are no longer adhered to the Matrigel-coated plate, they } \\
\text { can be pulled from suspension and transferred into a conical tube followed by } \\
\text { centrifugation at } 290 \mathrm{xg}(1200 \mathrm{rpm}) \text { for } 5 \text { min. Aspirate the supernatant and then } \\
\text { resuspend the cells in pre-warmed mTeSR medium for passaging. To improve cell } \\
\text { survival, supplement the mTeSR medium with } 10 \mu \mathrm{M} \text { of Y27632 for the first } 24-48 \\
\text { hours of culture }\end{array}$ \\
\hline 24 & $\begin{array}{l}\text { Overgrowth of differentiating } \\
\text { intermediate mesoderm cells }\end{array}$ & $\begin{array}{l}\text { The cells can be dissociated with } 0.05 \% \text { Trypsin-EDTA and plated at 1:4 splitting ratio } \\
\text { onto newly prepared laminin 511-E8-coated plates }\end{array}$ \\
\hline 23 and 24 & $\begin{array}{l}\text { Intermediate mesoderm } \\
\text { differentiation medium turns } \\
\text { yellow during culture. }\end{array}$ & $\begin{array}{l}\text { Refresh medium daily and if necessary, increase the volume of medium (for example, } \\
\sim 1.3 \mathrm{~mL} \text { of medium per } 12 \text {-well plate) }\end{array}$ \\
\hline 23 and 24 & $\begin{array}{l}\text { Detachment of intermediate } \\
\text { mesoderm cells from laminin } \\
\text { 511-E8-coated plate }\end{array}$ & $\begin{array}{l}\text { This can be avoided by passaging the intermediate mesoderm cells every } 10-14 \text { days } \\
\text { to a newly prepared laminin } 511 \text {-E8-coated plate. We have also found that the cells are } \\
\text { sensitive to fluctuations in the level of } \mathrm{CO}_{2} \text { in the incubator. We recommend checking } \\
\text { and calibrating the incubator } \mathrm{CO}_{2} \text { and humidity level regularly (at least once a week) }\end{array}$ \\
\hline Option A, xii & $\begin{array}{l}\text { Cell detachment after } 4-5 \text { days } \\
\text { of podocyte induction }\end{array}$ & $\begin{array}{l}\text { Replace induction medium with complete medium with CultureBoost-R and refresh } \\
\text { medium every } 2 \text { days. }\end{array}$ \\
\hline 23 and 24 & Cell death & $\begin{array}{l}\text { Test reagents for lot-to-lot variability. Also check and calibrate } \mathrm{CO}_{2} \text { and humidity } \\
\text { levels in the incubator }\end{array}$ \\
\hline $\begin{array}{l}\text { Box } 3 \text {, step } 10 \\
\text { Option B, steps } \\
\text { vii, ix, and x }\end{array}$ & $\begin{array}{l}\text { Fluid in microfluidic channels } \\
\text { drying up during ECM coating } \\
\text { or cell seeding }\end{array}$ & $\begin{array}{l}\text { Check that appropriate temperature and humidity levels are maintained in the } \\
\text { incubator. Also add water to sterile conical tube caps and place them in the petri dish } \\
\text { containing the microfluidic chips }\end{array}$ \\
\hline Option B, xii & $\begin{array}{l}\text { Temperature rising in incubator } \\
\text { while pump is running }\end{array}$ & $\begin{array}{l}\text { Some fluidic pumps get very hot during operation. We have previously observed this } \\
\text { problem while using syringe pumps for perfusion, but have not experienced similar } \\
\text { issue with the peristaltic pump listed under 'Equipment'. We recommend that the } \\
\text { incubator's temperature be monitored before and during operation of the pump. }\end{array}$ \\
\hline Option B, xiii & $\begin{array}{l}\text { Medium flowing too fast or } \\
\text { slow during perfusion }\end{array}$ & $\begin{array}{l}\text { Calibrate the peristaltic pump and check that the 2-stop tubing and cartridge are } \\
\text { properly secured to the pump }\end{array}$ \\
\hline $\begin{array}{l}\text { Box } 3 \text {, steps } 10 \\
\text { and } 14 \\
\text { Option B, vi }\end{array}$ & $\begin{array}{l}\text { Trapped air bubbles during } \\
\text { ECM coating or cell seeding in } \\
\text { the microfluidic chips }\end{array}$ & Remove ECM solution or cell suspension by pipetting and repeat the step slowly \\
\hline Box 3 , step 10 & Hydrophobic microfluidic chip & Check that the plasma treatment machine is working properly \\
\hline $\begin{array}{l}\text { Option B, step } \\
\text { vii } \\
\text { Box } 3 \text {, step } 16\end{array}$ & $\begin{array}{l}\text { Cells fail to attach to ECM- } \\
\text { functionalized chip }\end{array}$ & $\begin{array}{l}\text { Either start the experiment with new chips or decellularize the used chip followed by } \\
\text { baking at } 60^{\circ} \mathrm{C} \text { for a minimum of } 4 \text { hours, and then repeat plasma activation step. Also } \\
\text { check that the plasma machine is working properly. }\end{array}$ \\
\hline Option B, xii & $\begin{array}{l}\text { Medium reservoirs not flowing } \\
\text { equally }\end{array}$ & $\begin{array}{l}\text { Inspect chips for ruptured membrane or blockage by debris. Also check that 2-stop } \\
\text { tubing on pump and cartridge are properly secured to the pump. }\end{array}$ \\
\hline $\begin{array}{l}\text { Box } 3 \text {, step } 16 \\
\text { Option B, vi }\end{array}$ & Uneven cell seeding & $\begin{array}{l}\text { Cells too clumpy during seeding or cell seeding density is too low. Also consider } \\
\text { double seeding of the cells or prolonging the incubation time for seeding. For human } \\
\text { iPS cell-derived intermediate mesoderm cells, consider adding } 10 \mu \mathrm{M} \text { Y } 27632 \text { for first } \\
24 \text { hours of culture. }\end{array}$ \\
\hline
\end{tabular}

